\title{
Kein Zuckerschlecken für Spekulanten
}

\author{
Die Württembergische Gesellschaft für Runkelrüben-Zuckerfabrikation \\ $(1836-1854)^{*}$
}

Von Rainer Loose

\section{Anlass und Motiv}

In der Handelsbilanz des Königreichs Württembergs stellte die Einfuhr von $\mathrm{Zu}$ cker, Honig und Wachs einen ganz erheblichen Posten dar. Nach einer Aufstellung über den württembergischen Handel im Zeitraum 1811 bis 1821 wurde durchschnittlich Zucker im Wert von fast 660.000 fl eingeführt ${ }^{1}$. In der Kategorie „Gewerbserzeugnisse“ nahm Zucker den dritten Platz in der Einfuhrstatistik ein. Diese Summe wuchs in der volkswirtschaftlichen Gesamtrechnung weiter. 1826 schrieb der Präsident der „Centralstelle “2 des württembergischen landwirtschaftlichen Vereins, der Geheime Rat August von Hartmann (1764-1849), in einem Bericht an König Wilhelm I., dass sich die Einfuhr von westindischem Zucker im Wert von fast 1,5 Mio. Gulden nach und nach erübrigen werde, wenn es erst einmal

\footnotetext{
Für die Unterstützung meiner Studien zur Geschichte der Centralstelle des landwirthschaftlichen Vereins und insbesondere für die Recherchen im Archiv des Hauses Württemberg zur Zuckerfabrik Altshausen danke ich Herrn Dr. Eberhard Fritz, Althausen.

1 Württembergische Jahrbücher für vaterländische Geschichte, Geographie, Statistik und Topographie 6 (1823) S. 146.

${ }^{2}$ Die Schreibweise "Centralstelle“ mit „C“ am Anfang soll verdeutlichen, dass es sich, obwohl als Spitze eines landesweit agierenden Vereins konstituiert, sich um eine staatliche Behörde mit umfassenden Kompetenzen bei der Förderung der Landwirtschaft sowie von Gewerbe und Industrie handelte, welche von 1817 bis 1848 bestand und dem Innenministerium unterstellt war. Die wichtigste staatliche Aufgabe der Centralstelle war die Aufsicht über das Land- und forstwirtschaftliche Institut Hohenheim wie überhaupt die Sorge für das landwirtschaftliche Bildungswesen. Ihre Mitglieder, sämtlich Angehörige der damaligen adeligen, politischen und wirtschaftlichen Elite, berief der König persönlich, sodass ihre Empfehlungen über das ihnen eigene Netzwerk zu Regierung und Hof unmittelbar in Regierungshandeln umgesetzt werden konnte. Die Centralstelle wurde im März 1848 aufgelöst. Ihre Aufgaben gingen an die neue Zentralstelle für die Landwirtschaft und an die Zentralstelle für Gewerbe und Industrie über.
} 
ein befriedigendes Verfahren der Zuckerraffination aus Runkelrüben gäbe ${ }^{3}$.Zucker bildete einen unentbehrlichen Süßstoff nicht nur für die bürgerliche und adelige Tafel, sondern auch für den Tisch der ärmeren Landbevölkerung. Gesüßt wurden Speisen, Gebäck und Getränke wie Kaffee und Tee damals noch überwiegend mit Honig und importiertem Rohrzucker. Zucker war teuer, sodass sich viele Leute Gedanken machten, wie man aus den zuckerhaltigen Runkelrüben kristallisierten Zucker gewinnen könnte.

In Preußen hatte der Physiker und Chemiker sowie Pflanzenzüchter Franz Karl Achard 1801 eine erste Runkelrübenzuckerfabrik errichtet ${ }^{4}$. Die Ausbeute war gering, zudem aufwändig und teuer. Zwar wurden während der Kontinentalsperre die Verfahren der Zuckergewinnung aus Rüben verbessert, aber mit dem Ende der Herrschaft Napoleons 1813 überschwemmte der billigere Rohrzucker aus englischen Kolonien die mitteleuropäischen Märkte, sodass das Interesse an der Rübenzucker-Raffination nachließ. Dennoch blieb das Thema akut.

Im Königreich Württemberg fällt auf, dass besonders das der Centralstelle des landwirtschaftlichen Vereins unterstellte Land- und forstwirtschaftliche Institut in Hohenheim sich der Gewinnung von Zucker aus Runkelrüben widmete. Diese Beobachtung legt die Frage nahe, warum eine staatliche Bildungsanstalt gerade mit diesem doch eher der gewerblichen Wirtschaft zuzuordnenden Thema befasst war. Eine mögliche Antwort könnte sein, dass mit dem Bildungsauftrag des landwirtschaftlichen Instituts auch Forschungen zu aktuellen wirtschaftlichen Problemen des Landes verbunden waren und praktikable Lösungen von ihm erwartet wurden. Doch diese Vermutung findet in den Akten nur bedingt einen Anhalt. Vielmehr eröffnen Archivstudien in Stuttgart, Ludwigsburg und Altshausen ganz andere Perspektiven. Um die Ausführungen zu begrenzen, soll daher folgenden Fragen und Problemkreisen vorrangig nachgegangen werden:

1. Wie hat die königliche Regierung die Runkelrübenzuckergewinnung in Württemberg während der ersten Hälfte des 19. Jahrhunderts gefördert? Welche Institutionen und Personen waren hauptsächlich daran beteiligt?

2. Welche Möglichkeiten und Verfahren gab es überhaupt in der ersten Hälfte des 19. Jahrhunderts, um aus Runkelrüben Rohzucker herzustellen?

3. Welche Bedeutung hat die Zuckergewinnung als landwirtschaftlicher Industriezweig für die Erneuerung der Landwirtschaft in Württemberg? Welchen Beitrag leistet sie zur technologischen Entwicklung Württembergs?

${ }^{3}$ HStAS E 14 Bü 1124 (Mappe Correspondenzblatt 1821-51) n. 49 Bl.161. - Correspondenzblatt des württembergischen landwirthschaftlichen Vereins 9 (1826) S. 289.

${ }^{4}$ Zur Geschichte der Zuckerbereitung besonders aus Runkelrüben, vgl. Manfred Pobl: Südzucker 1837-1987. 150 Jahre Süddeutsche Zucker-Aktiengesellschaft Mannheim. Mainz 1987. S. 14-19. - Jakob Baxa: Art. ,Achard, Franz Karl'. In: NDB 1 (1953) S. $27-28$ (Onlinefassung http:// www.deutsche-biographie.de/pnd1188643622. html, Abruf 04.03. 2012). 


\section{Zum Stand der Zuckerfabrikation in Württemberg vor 1834}

Lange bevor die Centralstelle und damit auch das Land- und forstwirtschaftliche Institut Hohenheim sich der Frage der Runkelrüben-Zuckerfabrikation annahm, gab es Bemühungen, billigeren Zucker aus heimischen Rüben zu gewinnen. In Denkendorf hatte König Friedrich 1811 eine Fabrik für Runkelrübenzucker errichten lassen ${ }^{5}$. Dem Apotheker Morstadt, der der Zuckerfabrik vorstand, gelang es freilich nicht, obwohl er sich 1814 mit dem Zuckerfabrikanten Nathusius in Althaldensleben bei Magdeburg austauschte, die Zuckerausbeute in ein ausgewogenes Verhältnis von Kosten und Ertrag zu bringen. Sie blieb gering und war einfach zu teuer, sodass die Zuckergewinnung 1815 eingestellt wurde. Das Extrahieren des zuckerhaltigen Rübensaftes und die Verfahren, aus dem Saft den Kristallzucker auszufällen, gestalteten sich kompliziert und waren von vielen technischen und Vegetationsfaktoren abhängig.

Aus Gründen der Ausbildung spielte für die Centralstelle schon bei der Errichtung des Land- und forstwirtschaftlichen Instituts in Hohenheim die Rübenzuckergewinnung eine wichtige Rolle. Zugleich hoffte sie, ein Verfahren in Hohenheim entwickeln zu können, das die Zuckerraffination aus heimischen Runkelrüben im großen Maßstab wirtschaftlich erscheinen ließ. Präsident von Hartmann glaubte 1826 zwar fest daran, dass die Runkelrüben im Herbst für die Zuckerfabrikation in Hohenheim tauglich sein werden ${ }^{6}$, tatsächlich wollten sich keine Fortschritte einstellen.

Die ausbleibenden Erfolge machten es notwendig, sich mit allen auf diesem Gebiet tätigen Fachleuten auszutauschen. Die Centralstelle unterstützte Versuche, die ein kostengünstiges Extraktionsverfahren in Aussicht stellten. Zu diesem Zweck entsandte der Präsident von Hartmann 1829 den Sohn des Stuttgarter Apothekers Berg auf Staatskosten nach Frankreich, wo er die Verfahren von Crespel, Beaujeu, Chaptal und Dombasle genau studieren sollte ${ }^{7}$. Nach seiner Rückkehr wurde in Hohenheim eine Zuckerfabrik „im Kleinen“ errichtet, in welcher der junge Apotheker, ein Brunder des Architekten Ernst Berg, hauptsächlich Studierende unterrichten sollte ${ }^{8}$. Doch nicht Berg, sondern Professor Carl Göriz las ab 1831 in Ho-

${ }^{5}$ Vgl. Die Runkelrüben-Zuckerfabrikation in Denkendorf in den Jahren 1811-1815, nebst Nachrichten über den Fortgang dieses Industriezweiges in Frankreich und ihre Wichtigkeit im Allgemeinen, in: Correspondenzblatt (wie Anm.3) 9 (1826) S.259-292. - Pohl (wie Anm.4) S. 39. - Die Königlich Württembergische Lehranstalt für Land- und Forstwirthschaft. Hg. von der Centralstelle für Landwirthschaft. Stuttgart 1842. S. 16.

${ }^{6}$ HStAS E 14 Bü 1124 (Mappe Correspondenzblatt 1821-51) n. 49 Blatt 161v.

7 Mitteilung unter der Rubrik „Technische Reisen“ in: Correspondenzblatt (wie Anm. 3) 21/NF 1 (1832) S. 166; im Aufsatz von E. Berg in: Correspondenzblatt 27/NF 7 (1835) S. 257 das Jahr 1828.

${ }^{8}$ Das Neueste über die Runkelrüben-Zuckerfabrikation in Württemberg, in: Correspondenzblatt (wie Anm. 3) 21/NF 1 (1832) S. 274-278. 
henheim über Zuckerfabrikation ${ }^{9}$. Auf eigene Kosten errichtete der Architekt Berg in Denkendorf eine Zuckerfabrik.

Bedauerlicherweise verliefen die Versuche, aus Runkelrüben Zucker zu raffinieren, nur am Anfang erfolgreich. Was in der Theorie und im Labor im kleinen Maßstab so gut klappte ${ }^{10}$, erwies sich im Großen doch als ziemlich diffiziler Herstellungsprozess, bei dem nicht nur die technischen Apparaturen und chemischen Verfahren gut auf einander abgestimmt sein mussten, sondern auch die Qualität des zu verarbeitenden Rohmaterials, der Runkelrüben, einwandfrei zu sein hatte. Denn schon bald (1831) gab es in Denkendorf und Hohenheim unvorhergesehene Probleme, die der Architekt Berg in einem Brief an den König schilderte ${ }^{11}$. Welche Schwierigkeiten es genau waren, bleibt zunächst verborgen. $\mathrm{Zu}$ erfahren ist lediglich, dass am Ende die verdorbenen Runkelrüben sich nicht einmal an Bauern mit Viehhaltung verkaufen ließen, sodass ein zusätzlicher finanzieller Verlust entstand, der so nicht einkalkuliert war.

An der Reaktion des Staatssekretariates, welches prompt reagierte, erkennt man, dass die Ursachen beim und im Rohstoff gesucht wurden. Der Staatssekretär von Vellnagel wies nämlich die Centralstelle an, dass sie ihrerseits dem Landwirtschaftlichen Institut in Hohenheim den Auftrag erteile, 1832 auf 25 Morgen nur die gelbe Runkelrübe anzupflanzen ${ }^{12}$. Diesen Auftrag kann man so verstehen, dass die bisher verarbeiteten Rüben nicht von der besten Sorte und Qualität waren. Sie enthielten wegen des Witterungsverlaufs fast keinen oder zu wenig zuckerhaltigen Saft, was u. a. mit der Düngung des Bodens, der Bodenbearbeitung (fehlendes Hacken, Häufeln der Rübenbeete) während der Vegetationszeit und mit der Lagerung der Rüben nach der Ernte zusammenhängen könnte. Denn nach der Ernte sollten die Runkelrüben gegen Frost und Feuchtigkeit gut geschützt gelagert werden, was aber offensichtlich nicht der Fall gewesen war. Sie waren entweder zu lange in einer zu warmen Umgebung aufbewahrt worden und hatten ausgetrieben oder sie waren durch Frost geschädigt und matschig geworden, sodass kein zuckerhaltiger Saft extrahiert werden konnte. Ob dies in der Zuckerfabrik geschah oder auf den Feldern der Bauern, bleibt ungeklärt. Jedenfalls führte diese Erkenntnis dazu, dass die Centralstelle in einem Aufsatz über den neuesten Stand der Runkelrüben-Zuckerfabrikation $^{13}$ gleichsam als Mahnung festhielt, dass das Wesentlichste zum Ge-

${ }^{9}$ Günther Franz: Die Geschichte der Universität. In: Universität Hohenheim. Landwirtschaftliche Hochschule 1818-1968. Hg. von dems. Stuttgart 1968. S. 52.

10 Verwiesen sei auf die Beschreibung der Zuckerfabrikation von Johann Carl Leuchs: Die Zuker-Fabrikation oder Anleitung zur Erzeugung des Zukers aus Stärkemehl, Kartoffeln, Gummi, Papier, Stroh und Holz mit und ohne Schwefelsäure. Nürnberg ${ }^{2} 1835$ (Nürnberg $\left.{ }^{1} 1829\right)$. - Ludwig August Krause: Darstellung der Fabrikation des Zuckers aus Runkelrüben in ihrem gesammten Umfange. Wien 1834.

11 Correspondenzblatt (wie Anm. 3) 21/NF 1 (1832) S. 217-272.

12 Mitteilung der Centralstelle aus ihrem unmittelbaren Wirkungskreise, datiert 13. April 1832, in: Correspondenzblatt (wie Anm. 3) 21/NF 1 (1832) S. 271-271.

13 Correspondenzblatt (wie Anm. 3) 21/NF 1 (1832) S. 274-278. Hier S. 275. 
deiben der Runkelrüben-Zucker-Fabrikation, neben einem zweckmäßigen technischen Verfabren, auf einer, der Natur der Rüben an sich entsprechenden Behandlung derselben, und namentlich auf einer vorsichtigen Aufbewabrungsweise derselben [beruht].

Die Suche nach den möglichen Ursachen der gehaltlosen, beinahe zuckerfreien Runkelrüben konzentrierte sich nun auf die Rübensorten selbst und auf ein Verfahren, wie die Runkelrüben nach der Ernte bis zu ihrer Verarbeitung in der Fabrik sicher und ohne Saftverlust aufbewahrt werden könnten. Die Centralstelle veröffentlichte Abhandlungen, in denen der Wert und die Kultur der Runkelrüben genau beschrieben wurden, und hoffte, dass der Runkelrübenanbau sich mehr und mehr im Land verbreitete. Diese Sorge war berechtigt, da die Runkelrübe angeblich vom Vieh nur ungern gefressen wurde. Zudem ließ sie von verschiedenen Rübensorten, die sie in ihrem Versuchsgarten anbaute, im Hohenheimer Labor den Zuckergehalt bestimmen und kam zu der Erkenntnis, dass den höchsten Zuckergehalt die weiße französische Rübe enthalte ${ }^{14}$. Neben Anbauempfehlungen rückte die Centralstelle auch Auszüge aus Rechenschaftsberichten über die Runkelrübenverarbeitung in Hohenheim in das landwirtschaftliche Wochenblatt ein, so 1835 über die nur sechswöchige Kampagne (weil wegen der sommerlichen Trockenheit nicht genügend Rüben geliefert worden waren), deren Ergebnisse klar nachwiesen, dass die Herstellungskosten für ein Pfund Rohzucker im Durchschnitt etwas über 8 xr lagen und als Verkaufspreis je Pfund gut 13 xr hätten gefordert werden müssen, wenn sie wirtschaftlich hätte betrieben werden sollen ${ }^{15}$. Ein solcher Verkaufspreis war aber, verglichen mit dem Preis des importierten Kolonialzuckers, irreal. Die Runkelrüben-Zuckergewinnung blieb ein teures Unterfangen. Staat und Konsumenten zogen weiterhin keinen Gewinn daraus.

\section{Württembergische Pläne}

Wer die Literatur in den Journalen dieser Zeit verfolgt, kommt zum Schluss, dass die Bemühungen um eine profitable Zuckergewinnung von einer wirtschaftlichen Elite beobachtet wurden. Dinglers Polytechnisches Journal, das im Stuttgarter Cotta Verlag erschien, und das Polytechnische Centralblatt aus Leipzig wurden in hiesigen Bibliotheken und Lesegesellschaften (den bürgerlichen Museumsgesellschaften) gehalten und in Stuttgart und Hohenheim ziemlich gründlich ausgewertet, wie man an den im landwirtschaftlichen Wochenblatt eingerückten Auszügen unschwer feststellen kann. Interessierte Personen dürften über den Stand der $\mathrm{Zu}$ ckerfabrikation in Europa gut informiert gewesen sein. Es kann daher nicht ausge-

${ }^{14}$ So die Untersuchungen von Prof. Plieninger, dem wissenschaftlichen Sekretär der Centralstelle, im Jahr 1836; Correspondenzblatt (wie Anm. 3) 30/NF 10 (1836) S.233-237.

15 Wochenblatt für Land- und Hauswirthschaft und Handel 2 (1835) S. 97-99. 
schlossen werden, dass Leute mit Vermögen bald große Hoffnungen hegten und mancher Kaufmann schon blühende Geschäfte witterte. Daher verwundert es nicht, dass Ende Dezember 1834 die königliche Regierung in Stuttgart sich mit einem Gesuch konfrontiert sah, das der Ausschuss der Gesellschaft für Beförderung der Gewerbe in Württemberg dem Finanzminister von Herdegen vorlegte, in dem sie auf das Vorhaben des Heilbronner Kaufmanns C.C. Reuß aufmerksam machte, der eine Zuckerfabrik in Heilbronn errichten wollte ${ }^{16}$.

Der Kaufmann Reuß hatte sehr konkrete Vorstellungen, wie der Staat sein Projekt fördern könnte. Das Gebäude, das der Staat ihm unentgeltlich oder gegen mäBigen Mietzins überlassen sollte, war das ehemalige Karmeliterkloster mit dazugehöriger Scheuer in der Stadt Heilbronn. Außerdem forderte er 5.000 bis $6.000 \mathrm{fl}$ als zinsloses Darlehen aus der Staatskasse für die erste Einrichtung der Fabrik mit Maschinen und Apparaturen. Ferner bat er um Überlassung des erforderlichen Brennholzes aus den Staatswaldungen und um eine angemessene Prämie für den Export des Farinzuckers und Sirups ins Ausland. Aus der Distanz und Sicht von Stuttgart war dies ein beinahe unsittliches Ansinnen, das ein auf Sparsamkeit bedachter Finanzminister natürlich zurückweisen musste. Allenfalls akzeptieren konnte er die Überlassung eines Gebäudes aus Staatsbesitz. Alle anderen Forderungen überstiegen das Maß des Zumutbaren und Erträglichen, weshalb das Projekt schließlich scheitern musste.

Industrieansiedlung und Gewerbeförderung durch den Staat hatten im Württemberg des frühen 19. Jahrhunderts ihre ungeschriebenen Grenzen, wie das nächste Beispiel aus dem Frühjahr 1836 zeigt. Es handelt sich dabei um das Projekt der Kaufleute Müller und Hauf(f) in Tübingen ${ }^{17}$. Die beiden Kaufleute wandten sich am 29. April 1836 direkt an Wilhelm I. und baten ihn um die Überlassung des ehemaligen Akademie-Reitstalls der Universität, wofür sie $2000 \mathrm{fl}$ bezahlen wollten. Der König leitete das Gesuch an die zuständigen Ministerien der Finanzen und des Innern weiter. Die Minister (Schlayer und Herdegen) sahen zunächst kein Hindernis, zumal der alte Reitstall durch einen Neubau ersetzt worden war und daher sowieso veräußert werden sollte. Freilich war der Preis, den die beiden Tübinger Kaufleute boten, viel zu niedrig. Denn nach Erkundigungen beim Stadtschultheißenamt Tübingen waren Gebäude und Grundstück mindestens doppelt so viel wert. Wenigstens $4.000 \mathrm{fl}$ hätten die künftigen Zuckerfabrikanten schon bieten müssen, wenn der Deal hätte zustande kommen sollen. Sie besserten ihr Angebot auch nach, aber $3.000 \mathrm{fl}$ waren dem Finanzminister nicht genug, weshalb er eine Versteigerung vorschlug. Die interessierten Kaufleute hätten dann mitbieten können. Zweifel an der Sinnhaftigkeit des Vorhabens kamen den Ministern nicht zuletzt deswegen, weil sie Tübingen als Standort für eine Zuckerfabrik grundsätzlich

16 HStAS E 146 Bü 6083 n. 1 ad 1 (Note des Finanzministeriums an das Innenministerium betr. die Errichtung einer Zuckerfabrik in Heilbronn, datiert Stuttgart, 2. Dezember 1834).

17 HStAS E 146 Bü 6083 n. 3 (Eingabe betr.: Zuckerfabrikation in Tübingen 1836). 
für ungeeignet hielten. Sie führten an, dass eine solche Fabrik in einer Gegend, wo die höchsten Brennholzpreise des Königreichs bezahlt werden müssten, sich wirtschaftlich nicht betreiben lasse und deshalb Staat und Bevölkerung keinen Nutzen daraus zögen. Ob es zur Versteigerung des alten Akademie-Reitstalls kam und wer eventuell den Zuschlag erhielt, ist aus den vorliegenden Akten nicht ersichtlich.

Der dritte Fall, auf den hier eingegangen werden muss, ist tatsächlich ein Beispiel, welches gründlich geplant und realisiert wurde und welches vor allem nach einer Anlaufphase auch Gewinne zu machen versprach. Das Projekt, um das es hier geht, ist jenes einer Zuckerfabrik in Ulm, zu deren Gründung eine Gruppe von Gewerbetreibenden am 28. Februar 1836 aufgerufen hatte. Innerhalb von zwei Monaten sammelte sie $40.000 \mathrm{fl}$ Aktienkapital ein ${ }^{18}$. Der Verwaltungsausschuss der „Ulmer Runkel-Rüben-Zucker-Fabrikations-Gesellschaft“ schrieb Anfang 1837 einen Brief an den Innenminister und ersuchte ihn um ein Privileg, dergestalt, dass im Umkreis von vier bis sechs Stunden sich keine weitere Zuckerfabrik ansiedeln dürfe, da sie sonst keine Rüben preiswert einkaufen könnte ${ }^{19}$. Diesen Brief darf man durchaus als Reaktion auf entsprechende Pläne von zu gründenden Zuckerfabriken in Erolzheim ${ }^{20}$ und anderswo in Oberschwaben werten. Die Ulmer Zuckerfabrik war schon in der Aufbauphase weit fortgeschritten und suchte sich einen festumrissenen Einzugsbereich für den Anbau der benötigten Runkelrüben zu sichern. Der Rohstoffbezug musste im Hinblick auf das Anbaujahr 1837 jetzt mit den Mitteln des Ordnungsrechts abgesichert werden. Immerhin beschäftigte die Ulmer Zuckerfabrik schon 34 Arbeiter, besaß ein eigenes Fabrikgebäude, ein Magazin, einen Ochsenstall für 14 Ochsen, ein Waaghaus und ein Holzmagazin. Sie hatte inzwischen für den Ankauf von 10.000 Zentnern Rüben und für die Gebäude samt Inneneinrichtung rund $60.000 \mathrm{fl}$ ausgegeben ${ }^{21}$. Das Unternehmen arbeitete beim Abdampfungsprozess mit dem Patent des Dr. Zier, das der Ulmer Apotheker Gustav Leube ${ }^{22}$ für $2.000 \mathrm{fl}$ erworben hatte.

Da die Ulmer Zuckerfabrikationsgesellschaft ein staatliches Privileg beantragte, musste sie entsprechende Unterlagen an das Innenministerium einsenden. Diese

18 Peter Schaller: Wirtschaft und Gesellschaft (in Ulm). In: Ulm im 19. Jahrhundert (Forschungen zur Geschichte der Stadt Ulm. Reihe Dokumentation 7). Hg. von Hans-Eugen Specker. Ulm 1990. S. 121; anzufügen ist, dass die Ulmer Zuckerfabrik 1839 in Konkurs ging.

${ }^{19}$ HStAS E 146 Bü 6083 Unterfasz. 3, Beilage zu n. 1 (Brief an Excellenz [von Schlayer], datiert Ulm, 4. Januar 1837).

20 Die Zuckerfabrik in Erolzheim (OA Biberach) wurde 1836 von Freiherr von Bernhard gegründet, aber nach wenigen Jahren wieder aufgelöst, weil die Raffination nicht gelang; Jahrbücher (wie Anm. 1) 1839 S. 345. - Der Landkreis Biberach. Hg. von der Landesarchivdirektion Baden-Württemberg in Verbindung mit dem Landkreis Biberach. Sigmaringen 1987. Bd. I. S. 870.

${ }^{21}$ HStAS E 146 Bü 6083 Unterfasz. 3 n. 1 (Abschrift der Beschreibung der Ulmer Zuckerfabrik, datiert Ulm, 4. Januar 1837).

22 Der Ulmer Apotheker Dr. Ernst Gustav Leube war 1835 zum Mitglied des württembergischen landwirtschaftlichen Vereins ernannt worden. 
Pläne samt Beschreibungen übergab es der Centralstelle zur Prüfung. In dieser Hinsicht hatte aber die Centralstelle keine Einwände ${ }^{23}$. Ob daraufhin das gewünschte Privileg erteilt wurde, ist nicht bekannt. Ersichtlich ist aber, dass die Zuckerbereitung im Jahr 1837 keinen Gewinn abwarf und die Ulmer Zuckergesellschaft in finanzielle Nöte geriet. Um zu retten, was noch gerettet werden konnte, bedurfte es zur Überbrückung einer finanziellen Hilfe. Deshalb richtete die Gesellschaft an das Finanzministerium ein Gesuch um Unterstützung und bat um Gewährung eines zinslosen Kredits in Höhe von 25.000 Gulden $^{24}$. Diese Summe war dem Finanzminister freilich zu hoch, sodass er wie bisher grundsätzliche Bedenken und Zweifel an der Wirtschaftlichkeit der Zuckergewinnung aus Runkelrüben vortrug und meinte, dass trotz des hohen Importzolls auf Kolonialzucker noch lange keine Aussicht bestehe, dass der Rübenzucker genauso preiswert hergestellt werden könnte wie der importierte Rohzucker, wobei der billige Rohzucker hauptsächlich aus der holländischen Kolonie Java stammte, der rheinaufwärts die südwestdeutschen Märkte erreichte und dort von Raffineuren zur Kristallzucker verarbeitet wurde. Der Finanzminister lehnte ab und der Ausschuss der Ulmer Zuckergesellschaft versuchte es erneut; dieses Mal wollte er für ein staatliches Darlehen von $50.000 \mathrm{fl}$ einen Zins von 2 bis $2 \frac{1}{2}$ Prozent bezahlen ${ }^{25}$. Nachdem auch dieses Gesuch erfolglos blieb, ging die Ulmer Zuckergesellschaft in den Konkurs.

Nach wie vor hoffte man in Württemberg, ein eigenes Verfahren aus Runkelrüben Rohzucker zu extrahieren entwickeln zu können. Angewiesen blieb man weiterhin auf Informationen aus technisch höher entwickelten Ländern wie Frankreich, England, aber auch aus Preußen. Mitglieder der Centralstelle und des landwirtschaftlichen Vereins, die ins Ausland reisten, berichteten der Centralstelle und dem Innenministerium von ihren Erfahrungen und teilten Beobachtungen mit, wie in anderen Regionen und Ländern Zucker raffiniert wurde.

Doch nicht aus Frankreich oder England oder gar aus Preußen kam Hilfe, sondern aus dem benachbarten Großherzogtum Baden, wo ein in badischen Diensten stehender Freiherr aus dem württembergischen Assumstadt (OA Neckarsulm) Direktor des 1833 gegründeten großherzoglichen badischen landwirtschaftlichen Vereins geworden war, und welcher nicht nur gute Kontakte zu Karlsruher Hofund Finanzkreisen hatte, sondern auch eine Chance witterte, sein Wissen nutzbringend in den Aufbau einer gewinnträchtigen Industrie im Heimatland einzubringen. Diese Person war Freiherr Friedrich von Ellrichshausen (1792-1859), ein Bruder des zweiten Direktors des Hohenheimer Land- und forstwirtschaftlichen Instituts, Ludwig von Ellrichshausen, der 1832 verstorben war. In Baden und Karlsruhe war man einen Pulsschlag näher an Frankreich und beobachtete sehr

${ }^{23}$ HStAS E 146 Bü 6083 Unterfasz. 3 n. 4 (datiert Stuttgart, 27. Februar 1837).

${ }^{24}$ HStAS E 146 Bü 6083 Unterfasz. 3 n. 5 (Note des Finanzministerium an das Innenministerium, datiert Stuttgart, 10. Februar 1837).

${ }^{25}$ HStAS E 146 Bü 6083 Unterfasz. 3 n. 7 (Gesuch der Ulmer Zuckergesellschaft, Ablehnungsbescheid, datiert Stuttgart, 21. Februar 1838). 
genau, welche wirtschaftliche Neuerungen und technische Errungenschaften dort Einzug hielten. Auch der im folgenden Kapitel eine Schlüsselfigur bildende Erfinder Carl Sebastian Schü(t)zenbach (1793-1861) ${ }^{26}$ hielt sich längere Zeit in Frankreich auf, lernte die französische Lebensart kennen und schätzen, was u.a. zur Folge hatte, dass er seinen Namen nach französischer Manier und Aussprache Schuzenbach schrieb, obwohl er ja ein Südbadener und in Endingen bei Freiburg im Breisgau geboren war. Doch abgesehen davon, hatte Schützenbach sich gute Kenntnisse der französischen Maschinenbauindustrie erworben, die damals Vorbild für viele Länder Europas war und deren Fähigkeiten den bescheidenen Werkstätten Badens oder Württembergs weit überlegen waren.

\section{Schützenbachs Geheimnis und Patent}

Die negativen Erfahrungen mit den bisherigen Verfahren der Zuckergewinnung aus Runkelrüben machten die Centralstelle sensibel für andere Wege. Aufmerksam verfolgte man, wo in Europa Fortschritte bei der Zuckerfabrikation gemacht wurden und wusste, dass es nicht einfach war, die Runkelrübenzuckerfabrikation im Großen zu etablieren. Bestätigt fühlen durfte man sich in dieser Auffassung von den verschiedenerorts ausgelobten Preisaufgaben ${ }^{27}$, wie z. B. 1837/ 38, als der Verein zur Beförderung des Gewerbefleißes in Preußen eine goldene Denkmünze und 800 Taler demjenigen versprach, der eine genaue Untersuchung der Umstände vorlege, welche die Erzeugung von unkristallisierbarem Zucker bei der Darstellung des Runkelrübenzuckers bewirken. Die Preissumme sollte verdoppelt werden, wenn der Preisbewerber gleichzeitig mitteilte, wie die Bildung von unkristallisierbarem Zucker bei der Bereitung des Runkelrübenzuckers verhindert werden könnte und wie sich die angegebenen Maßnahmen und Mittel bei den anzustellenden Versuchen auf Dauer bewährten ${ }^{28}$. Die in dieser Preisaufgabe angesprochenen Probleme, die in dem technisch höherentwickelten Preußen noch einer Lösung verharrten, waren auch in Württemberg das Hauptproblem.

Besondere Erwartungen setzten Regierung und Centralstelle darum in das lange Zeit gut gehütete Geheimnis des Carl Sebastian Schützenbach. Dieser glaubte, in der Trocknung der Rübenschnitze ein Verfahren gefunden zu haben, mit dem sich Kristallzucker aus Runkelrüben in großen Mengen gewinnen ließe. Am 27. Mai 1836 hatte er für sein Verfahren ein Privileg auf die Dauer von zehn Jahren für das

${ }^{26}$ Sein Name wird auch abwechselnd Schuzenbach und Schutzenbach geschrieben; siehe seine Biographie von Carl Leisewitz: Art. ,Schützenbach, Sebastian Karl'. In: ADB 33 (1891) S. 152.

27 Selbst im industriell höher entwickelteren Frankreich lobte man noch 1837/38 hochdotierte Preise aus, die sich verschiedenen Problemen der Zuckerfabrikationen widmeten; (Dinglers) Polytechnisches Journal 1838 (68) S. 136-141.

28 Journal (wie Anm. 27) S. 320. 
Großherzogtum Baden erhalten ${ }^{29}$. Gleichzeitig suchte er ein solches Einführungspatent in anderen deutschen Bundesstaaten zu erlangen. Er lockte mit dem Versprechen, rund zehn Prozent Kristallzucker aus dem Rübensaft extrahieren zu können. Andere Verfahren begnügten sich mit bescheidenen fünf bis sieben Prozent. Man hielt das Schützenbach'sche Verfahren geradezu für umwälzend ${ }^{30}$ und sofort erregte die Schützenbach'sche Art der Rübenschnitztrocknung und der warmen Raffination des Zuckers ziemliches Aufsehen. Eile war geboten, weil mit der Errichtung des Deutschen Zollvereins hohe Importzölle auf Kolonialzucker eingeführt worden waren, um den noch wenigen Zuckerfabriken in den deutschen Staaten, vor allem in Preußen, einen Absatzmarkt zu sichern. Daraufhin schossen die Runkelrübenzuckerfabriken geradezu wie Pilze aus dem Boden. 1838 zählte man schon 21 Zuckerfabriken in den Staaten des Deutschen Bundes und weitere waren im $\mathrm{Bau}^{31}$, so auch in Württemberg. Eine breite Diskussion über die Vor- und Nachteile der Runkelrüben-Zuckergewinnung kam in Gang, so schon bei der Versammlung der ehemaligen landwirtschaftlichen Zöglinge in Hohenheim am 13. und 14. Mai $1836^{32}$. Vor allem die Frage nach dem Energieaufwand für das Trocknen der Rüben bestimmte die Diskussion ${ }^{33}$. Waren doch etliche Fachleute skeptisch, ob sich dadurch gegenüber der französischen Methode des Eindampfens des zuckerhaltigen Rübensaftes eine Kostenreduzierung bei der Kristallzuckergewinnung erzielen ließe. Erwartet wurde, dass der Verkaufspreis für ein Pfund Rübenzucker genau so niedrig sein sollte wie der des importierten Kolonialzuckers, was durchaus möglich erschien, weil der Importzoll, den der deutsche Zollverein seit 1834 auf Kolonialzucker aus England, Holland und Frankreich erhob, dem heimischen Runkelrübenzucker einen besonderen Preisvorteil gewährte.

Zumindest ein Ziel hatte Schützenbach sofort erreicht. Es bildete sich am 10. Juli 1836 eine badische Gesellschaft für Rübenzuckerfabrikation, in der das Karlsruher Bankhaus Salomon von Haber ${ }^{34}$ und der Direktor Friedrich von Ellrichshausen

29 Großherzoglich Badisches Staats- und Regierungsblatt 34 (1836) S. 228.

30 Wochenblatt (wie Anm. 15) 3 (1836) Nr. 28 vom 9. Juli 1836 S. 112.

31 Denkschrift den zwischen den Staaten des deutschen Zollvereins und dem Königreich der Niederlande am 31. Januar 1839 abgeschlossenen Handelsvertrag insbesondere dessen nachtheilige Einwirkung auf die Zuckerfabrikation in den Staaten des deutschen Zollvereins betreffend. Darmstadt 1840 (ein Exemplar im Bestand des Familienarchivs der Herren von Ellrichshausen, im StAL B 87 II Bü 844).

32 Wochenblatt (wie Anm. 15) 3 (1836) Nr. 27 vom 2. Juli 1836 S. 105-108.

33 Sie war u.a. Gegenstand einer Erörterung während der Versammlung deutscher Landwirte in Dresden im Oktober 1837, wo sich der Amtsrat und landwirtschaftliche Unternehmer Johann Gottlieb Koppe aus Preußen kritisch über die Vorteile der Schützenbachische Methode äußerte; ihm widersprach energisch der Direktor des badischen landwirtschaftlichen Vereins Friedrich von Ellrichshausen, siehe Amtlicher Bericht über die Versammlung deutscher Landwirte in Dresden im Oktober 1837. Hg. von H. W. Pabst und A. G. Schweitzer. Dresden/Leipzig 1838. S.60; die Frage der besten Methode der Zuckerraffination beschäftigte auch 1839 die Versammlung deutscher Land- und Forstwirte in Potsdam.

${ }^{34}$ Zur Familie des Bankiers Salomon von Haber, siehe Heinrich Schnee: Hofbankier Sa- 
des badischen landwirtschaftlichen Vereins führend waren. Die badische Zuckergesellschaft wollte umgehend eine Fabrik bauen, in der zunächst Rübenzucker im Kleinen hergestellt werden sollte, nicht zuletzt weil man in der Mitte des Jahres gar nicht mit größeren Mengen an Runkelrüben rechnen konnte, aber auch weil in den Reihen der Aktionäre die Skepsis über die „sagenhaften“ Erfolge des Schützenbach'schen Verfahren überwog und deshalb erst eine Probefabrik eingerichtet werden sollte. An Ort und Stelle sollte eine Prüfungskommission die Zuckergewinnung nach dem Schützenbach'schen Verfahren genau beobachten und ein Gutachten erstellen $^{35}$, so die Absprachen unter den Aktionären. Mit dem Bau dieser Fabrik wurde im August 1836 begonnen, und sie war im Februar 1837 in Ettlingen bei Karlsruhe soweit fertig gestellt, dass der Probebetrieb aufgenommen werden konnte. Inzwischen hatten Regierungen mehrerer deutscher Bundesstaaten ${ }^{36}$ ihr Interesse am Schützenbach'schen Verfahren angemeldet und Kontakte zur badischen Gesellschaft für Zuckerfabrikation aufgenommen.

Im Gegensatz zu anderen Verfahren wurden bei der Schützenbach'schen Methode zuerst die Rüben mit Schneid- und Hackmaschinen zerkleinert und die Schnitze dann in speziellen Öfen getrocknet, wobei ihnen der Großteil des Wassers (ca. 70 Prozent) entzogen wurde. Sie waren somit „konserviert“, verdarben nicht mehr so rasch und konnten je nach Bedarf in den Produktionsbetrieb eingebracht werden; eine ganzjährige Zuckerkampagne schien möglich zu werden. Anschließend wurden die getrockneten Rübenschnitze zermahlen und unter Zusatz von erwärmtem Wasser langsam bei mittlerer Hitze gekocht. Der zuckerhaltige Saft wurde nicht wie bei anderen Verfahren mit Hilfe von Alkohol (Weingeist), sondern durch warmes Wasser mit schwacher Schwefelsäure ausgezogen. Der trübe Zuckersaft musste anschließend von Eiweiß, Schleimzucker, Bitterstoffen, Säuren und anderen Fremdstoffen durch Kochen unter Beigabe von Blut oder Milchfett gereinigt und daraufhin durch Beinschwarz (= Knochenkohle) gefiltert werden, bis der Saft klar und soweit eingedickt war, dass die Melasse abgeschieden und der Zucker gedeckt werden konnte, wo er in einem langsam verlaufenden Prozess auskristallisierte.

Diese Methode konkurrierte mit der „französischen Methode“, die in Süddeutschland hauptsächlich mit dem Namen des Bergwerksdirektors Dr. Reichenbach aus Blansko in Mähren verbunden ist. Carl Ludwig (von) Reichenbach war

lomon von Haber als badischer Finanzier. In: ZGO 109 (1961) S. 341-359.

${ }^{35} \mathrm{Vgl}$. die „Statuten der badischen Gesellschaft für Zucker-Fabrikation“ (datiert Carlsruhe, 16 Juli 1836), Exemplar in StAL E 173 III Bü 6088 (Fabriken im Oberamt Neckarsulm 1836-1840).

${ }^{36}$ U.a. das Großherzogtum Hessen, die Königreiche Bayern und Preußen; in Bayern und Preußen scheiterte Schützenbach mit seinem Patentwunsch; in Frankreich bediente sich Schützenbach des Bankiers Jordan de Haber, Sohn des Karlsruher Bankiers Salomon von Haber, wo er sich Patentrechte im April, August und September 1837 sicherte; Journal (wie Anm. 27) S. 313-314 (Neue Patente, welche in Frankreich im 2. und 3. Trimester 1837 in betreff der Zuckerfabrikation genommen wurden). 
1788 in Stuttgart geboren und nach seinem Studium in Tübingen nach Mähren ausgewandert, wo er in die Dienste des Grafen Salm trat ${ }^{37}$. Reichenbach betonte, dass er keine Erfindung gemacht habe, sondern lediglich Verbesserungen an bereits bekannten Verfahren der Zuckerextraktion aus Runkelrüben vorgenommen habe. Er baue ja auf dem Wissen und den Erfahrungen seiner Vorgänger auf und wolle deshalb keinen Patentschutz beanspruchen, sondern gab bereitwillig jedermann Auskünfte über seine Methode und seine Konstruktionen ${ }^{38}$. Bei seinem Verfahren wurden die Rüben nach dem Waschen zerhackt, in einem Macerator (Zerkleinerer, Zerhacker von faserigen Stoffen) mit mehreren Kammern jeweils eine halbe Minute lang heißem Wasser und Dampf ausgesetzt, sodass die Schnitze weich wurden, dabei aber das Zellgewebe nicht zerstört und nur der zuckerhaltige Saft ausgezogen wurde. Über eine im Macerator angebrachte sinnreiche Wellenanordnung wurden die Schnitze im Halbminutentakt von Kammer zu Kammer transportiert, bis in der letzten Kammer die Rübenschnitze kaum noch Zucker enthielten. Reichenbach nannte deshalb seinen Macerator „Edulcator“ (= Aussüsser) ${ }^{39}$. Anschließend wurde der klare Saft, der keinen Schleimzucker und nur noch geringe Mengen an eiweißhaltigen Stoffen enthielt, in der Siedehitze zu Sirup eingekocht, dann durch Knochenkohle gefiltert, um letzte Bitterstoffe auszuscheiden und bis auf die Probe eingedickt ${ }^{40}$.

Damit lagen die Vorteile von Schützenbachs Verfahren auf der Hand. Es sicherte bei einem hohen Energieaufwand eine gleichmäßige Auslastung des Produktionsbetriebs während des ganzen Jahres, da die getrockneten Rübenschnitze nur dann zur eigentlichen Zuckerfabrikation verbraucht wurden, wenn die Maschinen und Apparaturen in Betrieb waren. Bedingung war, dass die getrockneten Rübenschnitze in einem gut belüfteten Raum aufbewahrt wurden. Neben dem hohen Energieverbrauch zum Trocknen der Rübenschnitze bildeten die Kosten für das Trocknungshaus, das getrennt vom Siedehaus errichtet werden musste, und ein besonderes Lagergebäude, welche einen zusätzlichen Kapitalaufwand erforderten, die größten Nachteile.

37 Michael Engel: Art. ,Reichenbach, Karl Ludwig Friedrich Freiherr von'. In: NDB 21 (2003) S. 305-307 (Onlinefassung URL: http://www.deutsche-biographie.de/pnd 1070509 78. html, Abruf 04. 03. 2012). - Maria Habacher: Christian Ferdinand Hochstetter und Karl Ludwig Freiherr von Reichenbach. Zur Naturforschung und Industrialisierung im Vormärz. In: Jahrbuch für Geschichte der oberdeutschen Reichsstädte. Esslinger Studien 16 (1970) S. 171-227. - Biographisches Lexikon des Kaiserthums Österreich. Hg. von Constantin von Wurzbach. Wien 1873. Bd.25. S. 169-177.

${ }^{38}$ So u.a. der russische Staatsrat von Masseloff, der 1841 Reichenbach in Blansko und Wien besucht hatte; Oekonomische Neuigkeiten und Verhandlungen 65 (1843) S. 389-390.

39 Reichenbach beschrieb sein Verfahren in einem Aufsatz ausführlich 1838 in Journal (wie Anm. 27) S. 281-294, weil er sich von seinen Kritikern missverstanden fühlte.

${ }^{40}$ So in Kurzform die Angaben von dem Altshauser Fabrikdirektor Schmidt in seinem Bericht über die Besichtigung der Ettlinger Fabrik vom 29. April 1837 (StAL B 87 II Bü 844). 
Bei Reichenbachs französischer Methode konzentrierte sich die Zuckergewinnung auf das Ausziehen des zuckerhaltigen Saftes aus den grünen Runkelrüben, die freilich rasch verarbeitet werden mussten, weil sie, ob in Kellern oder Gruben eingeschlagen, mit der Zeit zuckerhaltigen Saft verloren und keimten. Ebenso musste der Zuckersaft rasch konzentriert werden, da er sonst an der Luft trüb und bitter werden konnte. Das Reichenbach'sche Edulcationsverfahren benötigte große Maschinen und erforderte einen geschlossenen Verarbeitungskreislauf; ein Produktionsprozess, der gleichsam Tag und Nacht in Gang zu halten war, bis auch die letzten Runkelrüben verarbeitet waren. Zuverlässige Arbeiter und Techniker, aber auch gute Konstrukteure, die allfällige Reparaturen und Verbesserungen an den Maschinen vornehmen konnten, waren unabdingbar, aber daran und am nötigen Knowhow fehlte es in Württemberg, aber auch in Baden.

\section{Die Anfänge der württembergischen Gesellschaft für Zuckerfabrikation}

Wie angedeutet, gehörte auch die württembergische Regierung zu den Interessenten Schützenbachs. Sie hatte mit Zustimmung der Centralstelle des landwirtschaftlichen Vereins, die als Gutachterin tätig geworden war, am 11. August 1836 Schützenbach das gewünschte Privileg erteilt ${ }^{41}$. Das Gutachten legte die Centralstelle ihrem Mitglied, dem Staatsrat von Kielmeyer vor, der sich in seiner Stellungnahme kritisch zu den Verbesserungen der Zuckerherstellung durch Schützenbach äußerte. Doch am Ende empfahl er der Centralstelle und dem Innenministerium das nachgesuchte Einführungspatent zu erteilen ${ }^{42}$. Schützenbach seinerseits trat dem Freiherrn von Ellrichshausen das ihm von der württembergischen Regierung eingeräumte Privileg für den Bereich der Oberämter Neckarsulm und Heilbronn vertraglich am 24. September $1836 \mathrm{ab}^{43}$, was damit zu tun hatte, dass Ellrichshausen auf seinem Rittergut Maisenhälden die erste Zuckerfabrik in Württemberg nach dem Schützenbach'schen Verfahren errichten wollte. Publik wurde diese Absicht, als er gut eine Woche später ein Gesuch an den König richtete und ihn um die Genehmigung für den Bau einer Zuckerfabrik in Maisenhälden ${ }^{44}$ bat. Er beabsichtigte nach dem erfolgreichen Probebetrieb in Ettlingen sofort mit den Bauar-

41 Württembergisches Regierungsblatt Jg. 1836 S. 370 (Bekanntmachung des Innenministeriums vom 23. 8. 1836). - Pobl (wie Anm. 4) S. 39; Gutachter war der wissenschaftliche Sekretär der Centralstelle Professor Plieninger gewesen.

${ }^{42}$ HStAS E 146 Bü 6084 n. 6 (Die Centralstelle übersendet das Gutachten von Staatsrat von Kielmeyer dem Innenministerium, datiert Stuttgart, 9. Juli 1836).

${ }^{43}$ StAL E 173 III Bü 6088 (Abschrift des Vertrags zwischen dem Chemiker und Fabrikanten Schuzzenbach [sic!] zu Freiburg in Breisgau und dem Director von Ellrichshausen zu Carlsruhe, datiert Carlsruhe, 24. September 1836, beglaubigt durch das Stadtrevisorat Carlsruhe, 27. September 1836).

${ }^{44}$ StAL E 173 III Bü 6088 n.14; das Gesuch datiert mit Maisenhelden, 2. Oktober 1836. - Beschreibung der freiherrlich von Ellrichshausen'schen Besitzungen in StAL E 156 Bü 142 
beiten zu beginnen, damit im Herbst 1837 in Maisenhälden die Zuckerfabrikation aufgenommen werden könne. Der König leitete das Gesuch an den Innenminister weiter, und dieser erlaubte mit Hinweis auf die Gewerbeordnung, welche in diesem Punkt kein aufwändiges Genehmigungsverfahren vorsah, am 17. Oktober 1836 den Bau der Fabrik ${ }^{45}$. Ellrichshausen hatte seinem Schreiben an den König noch die Bemerkung angefügt, dass er Personen einlade, welche eine Gesellschaft für diesen Industriezweig bilden wollten; er glaube, dass er seinem Vaterlande damit einen Dienst erweisen könne.

Um sich eine eigene Anschauung von der Brauchbarkeit der Schützenbach'schen Methode zu machen, entsandte auch die königliche Regierung Fachleute nach Ettlingen, unter ihnen Professor Plieninger von der Centralstelle ${ }^{46}$. Dort prüften sie mehrere Tage lang während der Kampagne des Frühjahrs 1837 die Schützenbach'sche Methode ${ }^{47}$. Den Bericht, den sie darüber erstellten ${ }^{48}$, ließ die Centralstelle ebenfalls von ihrem Mitglied Professor Kielmeyer überprüfen. Dieser gab abermals sein Plazet, sodass sich nun auch in Württemberg eine Gesellschaft für Zuckerfabrikation aus Runkelrüben Mitte April 1837 bildete, welche sogleich einen Vertrag mit Schützenbach abschloss, in dem sich dieser alle Rechte an seinem Verfahren für den Bereich des Königreichs Württemberg sicherte und jede Neuerung und Verbesserung abzutreten verpflichtete, insbesondere aber mit Zustimmung des Freiherrn von Ellrichshausen in Karlsruhe sich sämtliche Rechte für die Oberämter Heilbronn und Neckarsulm einräumen ließ.

Der Rechtsform nach war diese eine Aktiengesellschaft mit einem Stammkapital von einer Million Gulden. Jede Aktie kostete $500 \mathrm{fl}$ und durfte nicht gestückelt werden $^{49}$. In das Direktorium der württembergischen Gesellschaft für Zuckerfabrikation wurde am 1. Juni 1837 Professor Plieninger ${ }^{50}$, wissenschaftlicher Sekretär

(Einweisung der Freiherren von Ellrichshausen zu Assumstadt [OA Neckarsulm] in die Surrogate der Polizei-Verwaltung 1822-1846).

45 StAL E 173 III Bü 6088 n. 14 (Anweisung der Innenministers von Schlayer an die königl. Kreisregierung in Ludwigsburg, Stuttgart 17. Oktober 1836).

${ }_{46}$ HStAS E 146 Bü 6084 n. 20 (Die Centralstelle unterrichtet den Innenminister von der Nominierung Prof. Plieninger für die nach Ettlingen abzusendende Kommission, datiert Stuttgart, 2. Dezember 1836).

47 In diesem Zusammenhang sei erwähnt, dass auch in Ludwigsburg sich ein Verein für Zuckerfabrikation aus Runkelrüben unter der Leitung von General-Lieutenant von Röder gebildet hatte, der im Frühjahr 1838 einen Probeversuch aus Runkelrüben Zucker zu gewinnen machte; Correspondenzblatt (wie Anm. 3) 34/NF 14 (1838) S. 135-136.

${ }^{48}$ Ueber die Trocknungsmethode der Rüben bei der Zucker-Fabrikation. In: Correspondenzblatt (wie Anm. 3) 33/NF 13 (1838) S. 11.

${ }^{49}$ Statuten der Württembergischen Gesellschaft für Zucker-Fabrikation. Stuttgart 1837. $\$ 2$.

50 Dieser besaß eine Aktie à $500 \mathrm{fl}$; als Mitglied der Centralstelle verfolgte er zugleich die württembergischen Interessen; erhielt er doch bei der Wahl in das Direktorium 1837 die meisten Stimmen. 
der Centralstelle und Aktionär, gewählt, was der König begrüßte ${ }^{51}$, nicht zuletzt weil er selbst achtzig Aktien im Gesamtwert von $40.000 \mathrm{fl}^{52}$ gezeichnet hatte. Ihn vertrat in den Aktionärsversammlungen einer der Kuratoren seines Privatvermögens, der Staatsrat und Hofdomänenkammer-Direktor von Gärttner, der ebenfalls Aktionär geworden war. Aktien hatten ferner u. a. gezeichnet: Prinz Friedrich von Württemberg, Großherzogin Stephanie von Baden in Mannheim, die Markgrafen Wilhelm und Maximilian von Baden, der Erbprinz von Sigmaringen, der Fürst von Fürstenberg in Donaueschingen, Freiherr Götz von Berlichingen in Jagsthausen, Innenminister von Schlayer, Außenminister Graf von Beroldingen, der Redakteur des Schwäbischen Merkur Elben, der Redakteur des Deutschen Courier Dr. Weiß, der königliche Stallmeister Freiherr von Taubenheim, Freiherr Ernst Gustav von Ellrichshausen (Adjutant des Königs und Rittmeister in Stuttgart) ${ }^{53}$, Freiherr Friedrich von Ellrichshausen, Direktor des badischen landwirtschaftlichen Vereins, Freifrau von Ellrichhausen (geborene Gräfin von Beroldingen, Ehefrau des Freiherrn Ernst von Ellrichshausen), der erste Adjutant des Königs General-Lieutenant von Spitzemberg und der Oberstlieutenant von Troyff (Kommandant der königlichen Leibgarde) ${ }^{54}$. Insgesamt aber überwog der Stimmenanteil nicht-württembergischer Aktionäre ${ }^{55}$, was mit der Dominanz der badischen Großaktionäre, nämlich des Karlsruher Bankhauses Haber (400 Aktien) und des Chemikers Schützenbach (500 Aktien), zusammenhängt. Architekt E. Berg aus Stuttgart wurde im Sommer 1837 zum Fabrikdirektor der Gesellschaft für Züttlingen bestellt und nicht zuletzt deshalb wenig später zum Mitglied des württembergischen landwirtschaftlichen Vereins ernannt, weil er - so die Begründung seiner Aufnahme ${ }^{56}$ - interessante Mitteilungen über die Zuckerfabrikation lieferte.

${ }^{51}$ HStAS E 146 Bü 7653 n. 10 (Anzeige des Präsidenten von Hartmann vom 14. Juni 1837) und n. 12 (Mitteilung des Staatsekretärs von Vellnagel an das Innenministerium, der König habe keine Einwände, datiert 20. Juni 1837).

52 Archiv des Hauses Württemberg Altshausen. Hofdomänenkammer Bü 335 (Zuckerfabrik Altshausen), n. 1 (Der König weist die Kuratoren seines Privatvermögen an, 80 Aktien im Betrag von $40.000 \mathrm{fl}$ für die zu gründende württembergische Gesellschaft für Zuckerfabrikation aus Runkel-Rüben zu zeichnen, datiert Stuttgart, 20. April 1837 mit eigenhändiger Unterschrift des Königs).

53 Jüngster Bruder des Freiherrn Ludwig von Ellrichshausen, Direktor des Landwirtschaftlichen Instituts in Hohenheim (1789-1832) und Bruder von Friedrich von E., Direktor des großherzoglichen badischen landwirtschaftlichen Vereins (1792-1859), vgl. Die Freiherren von Ellrichshausen. In: Heimatbuch Jagstheim. Hg. von Hans-Joachim König. Crailsheim 1990. S. 41-44.

${ }^{54}$ Gedrucktes „Verzeichnis der Actionäre der Württembergischen Gesellschaft für Zucker-Fabrikation“. Stuttgart 1837 mit 175 Namen (im Archiv des Hauses Württemberg Altshausen. Hofdomänenkammer Bü 335).

551838 entfielen auf Württemberg 552, auf Baden 728 und auf das übrige Ausland 220 Aktienstimmen (Protokoll der Generalversammlung der Württembergischen Gesellschaft für Zuckerfabrikation vom 30. November 1838).

${ }^{56}$ HStAS E 14 Bü 1123 n. 45 ad 44 („Verzeichniß etwa neu aufnehmender Mitglieder“, datiert Stuttgart, 12. Oktober 1838). 
Das siebenköpfige Direktorium hatte die Aufgabe eine Zuckerfabrik in Züttlingen im Oberamt Neckarsulm, d.h. auf dem Grund und Boden des Direktors Friedrich von Ellrichshausen, zu errichten und Aufbau und Betrieb so zu organisieren, dass mit der Zuckerfabrikation im Herbst/Winter 1837/38 begonnen werden konnte. Vorgesehen war zunächst eine Verarbeitungskapazität von 10.000 Zentner Rohzucker. Daraus ergab sich die Notwendigkeit, Verträge mit Bauern in den Oberämtern Neckarsulm und Heilbronn über die Lieferung von Runkelrüben im Herbst $1837^{57}$ abzuschließen und Vorkehrungen für die Rübenlagerung zu treffen $^{58}$ sowie Bauaufträge für ein Trocknungshaus zu vergeben, damit die Rübenernte nicht vorzeitig verdarb. Mitte November 1837 schrieb Architekt Berg an den Rittmeister Ernst von Ellrichshausen in Stuttgart, dass das Etablissement in Züttlingen soweit fertiggestellt sei, dass Ende November mit dem Trocknen der Rüben begonnen werden könne ${ }^{59}$. Auch der Raffineur Bonatz aus Hamburg sei angekommen und werde mit ihm gemeinsam das Werk in Gang setzen. Bonatz sollte aus dem Rohzucker Kristallzucker raffinieren.

Die Vorzeichen standen gut, und Friedrich von Ellrichshausen wünschte eine Erweiterung der Aktivitäten der württembergischen Zuckergesellschaft auf Oberschwaben, wobei nicht eruiert werden kann, ob dies sein eigener Wunsch war, oder ob er sich nicht geschickt einen Wunsch des Königs zu eigen machte. Noch vor Weihnachten 1837 kam eine Vereinbarung über die Abtretung der Rechte am Schützenbach'schen Verfahren durch von Ellrichshausen an die Württembergische Zuckergesellschaft zustande ${ }^{60}$, eine wichtige juristische Voraussetzung, um in anderen Landesteilen eine Zuckerfabrik nach dem Schützenbach'schen Muster errichten zu können. Darin verpflichtete sich die Württembergische Gesellschaft zum Bau einer zweiten Zuckerfabrik auf einer vom König zu bestimmenden Domäne.

Der Wunsch, neben Züttlingen auch in Oberschwaben eine Zuckerfabrik zu errichten, stieß bei König Wilhelm I. nicht allein auf formale Gegenliebe, sondern auch auf aktive Unterstützung aus seinem Privatvermögen. Schon im Juni 1836 hatte er den Wunsch geäußert ${ }^{61}$, auf den bei Altshausen gelegenen großen Moor-

57 Direktion der württembergischen Zuckergesellschaft rückte in das Heilbronner Intelligenzblatt einen Aufruf (datiert Stuttgart, 21. April 1837) ein, im Herbst Runkelrüben nach Maisenhälden zu liefern; wer sich dazu vertraglich durch Ausfüllung und Zusendung des beigedruckten Formulars verpflichtete, durfte mit 30 xr je Zentner Rüben rechnen; Beilage zum Heilbronner Intelligenzblatt Nr. 94.

${ }_{58} \mathrm{Zu}$ diesem Zweck pachtete die Zuckergesellschaft den hinteren Teil des Keltergebäudes in Züttlingen von Freiherrn von Ellrichshausen; StAL B 87 II Bü 844 (Pachtvertrag auf drei Jahre abgeschlossen am 1. September 1837).

59 StAL B 87 II Bü 844 (datiert Assumstadt, 14. November 1837).

60 StAL B 87 II Bü 844 (datiert Illingen, 18. Dezember 1837).

61 Archiv des Hauses Württemberg Altshausen. Hofdomänenkammer Bü 335 n. 7, Schreiben des Direktoriums und des Ausschusses der württembergischen Zuckergesellschaft an eine unbekannte Excellenz (wahrscheinlich von Gärttner), datiert Stuttgart, 9. Juni 1837, in 
gründen Runkelrüben anzupflanzen ${ }^{62}$. Sie gehörten wie die zur ehemaligen Deutschordenskommende gehörigen Hofgüter zu seinem von der Hofdomänenkammer und besonders eingerichteten Hofkameralämtern verwalteten Privatvermögen. Tatsächlich wollte der Hofkammer-Direktor von Gärttner Ende Dezember 1837 vom Altshauser Hofkameralverwalter Vogel wissen, wo in Altshausen und Umgebung ein passendes Gelände für die zu gründende Zuckerfabrik im Oberland verfügbar sei; er benötige diese Angaben bis zur Generalversammlung im Februar $1838^{63}$. Diese Informationen gingen rechtzeitig in Stuttgart ein. Die Generalversammlung beschloss daher am 17. Februar 1838 eine zweite Runkelrübenzuckerfabrik mit Trocknungs- und Siedhaus in Altshausen ebenfalls mit einer Kapazität von 10.000 Zentnern Rohzucker zu bauen. Zu diesem Zweck, aber auch um das noch fehlende Siedhaus in Züttlingen zu errichten, sollten die Aktionäre dreißig Prozent des Aktienkapitals umgehend einzahlen.

Beim Aufbau der Altshauser Zuckerfabrik scheint es jedoch unvorhergesehene Schwierigkeiten und Konflikte gegeben zu haben. Aus einem Brief, den Schützenbach an die Direktion der württembergischen Zuckergesellschaft am 28. April 1838 schrieb $^{64}$, geht hervor, dass der Architekt Berg in Züttlingen die Einrichtung der Trocknungshäuser und der Siederei nicht nach seinen Plänen ausführte, sodass er befürchtete, die andere Einrichtung gefährde den gesamten Erfolg seines Unternehmens. Schützenbach fügte an, dass die von Architekt Berg konstruierten Öfen in Züttlingen ganz unzweckmäßig seien und viel mehr Brennmaterial erforderten als von ihm berechnet. Auch in Altshausen, wo im zeitlichen Abstand von einem halben Jahr ebenfalls eine Zuckerfabrik nach dem Muster von Züttlingen errichtet wurde, fuhr Schützenbach fort, habe die Direktion einen Bauleiter eingesetzt, der ganz wirre Ansichten von der Zuckergewinnung habe; er wisse nicht einmal, dass der Dampf über eine Röhre 50 Schritt und mehr vom Dampfkessel in den Siederaum geleitet werden könne und verstoße mit seiner Anordnung sogar gegen Gesetze und Schutzvorschriften, die den Dampfkessel in einem besonderen Gebäude außerhalb der eigentlichen Siederei vorschrieben. Der im Bau befindliche Trocknungsofen sei unbrauchbar und müsse durch einen neuen ersetzt werden. Wenn der Fabrikdirektor Schmidt in Altshausen weiterhin im Amt bleibe, sehe er sich ge-

dem es heißt, dass man von dem Wunsch des Königs wisse, in Altshausen eine Zuckerfabrik zu errichten, jedoch könne man wegen der fortgeschrittenen Jahreszeit keine Rübenkontrakte in Oberschwaben abschließen; der Transport von 5.000-6.000 Zentnern getrockneter Rübenschnitze aus Züttlingen nach Altshausen sei aber zu teuer.

${ }^{62}$ Faksimile des Schreibens von Staatssekretär von Vellnagel an den Hofkameralverwalter Vogel in Altshausen vom 6. Juni 1836 - Stuttgart, in: Josef Miller, Walter Ebner: 150 Jahre Zuckerfabrik Altshausen. In: Beiträge zur Kulturgeschichte von Altshausen und Umgebung 11 (1988) S. 129-131. Hier Nr.10 S. 130.

63 Archiv des Hauses Württemberg Altshausen. Hofdomänenkammer Bü 335 (Abschrift eines Schreibens des Staatrats und Hofkammer-Direktors von Gärttner an den Hofkameralbeamten Vogel, datiert Stuttgart, 28. Dezember 1837).

${ }^{64}$ StAL B 87 II, Bü 844. 
zwungen, seine Mitwirkung aufzukündigen. Der Gesellschaft überlasse er eine Kopie seiner Baupläne, die er soeben mit der Firma Lesnier in Paris ausgearbeitet habe, und bat, seine Vorschläge bei den Bauten in Altshausen unbedingt zu befolgen.

Um seiner Forderung Nachdruck zu verleihen, unterrichtete Schützenbach auch das Bankhaus Haber, welches nun befürchtete, es könnte das viele Geld durch unfähige Bauführer in den Sand gesetzt werden. Der Bankier von Haber reagierte umgehend und äußerte seine Bedenken in einem Brief an Friedrich von Ellrichshausen in Karlsruhe und ließ wissen, er erwäge, die Einzahlung des restlichen Aktienkapitels zum Monatsende Mai 1838 auszusetzen ${ }^{65}$. Ellrichshausen teilte dies eilig seinem Bruder in Stuttgart mit, der als Adjutant des Königs enge Kontakte zu diesem und anderen einflussreichen Personen des Hofes hatte, und meinte, dass die Stimmung in Karlsruhe für die Auflösung der württembergischen Aktiengesellschaft sei, da die badischen Aktionäre kein Vertrauen in die Direktion mehr hätten.

Doch so weit kam es nicht. Eine außerordentliche Aktionärsversammlung im Mai 1838 räumte den verantwortlichen Direktoren nochmals eine Chance ein, zumal auch die kritisierten Fabrikdirektoren in die Offensive gingen und Fachleute um Überprüfung baten. Einer dieser Fachmänner war der Hofkammer-Baumeister Gaab. Gaab visitierte die Bauten in Züttlingen und Altshausen und fand die Ausführung der Fabrikgebäude ganz passend. Ein anderer Fachmann war der Wasserbau-Direktor Duttenhofer, der die äußeren Triebwerksanlagen inspizierte und auch diese in Ordnung fand. Damit wich der Druck vorerst, aber das Misstrauen blieb. Schließlich räumten die Mitglieder des Direktoriums ihren Platz und traten zurück. In dieser angespannten Situation konnte auch die Überreichung einer ersten Probe des in Züttlingen gewonnenen Zuckers Anfang September 1838 an den König nichts ändern ${ }^{66}$. Der sichtbare Beweis einer gelungenen Zuckerraffination genügte den Kritikern nicht mehr.

Die badischen Aktienvertreter sahen jetzt ihre Chance, das Direktorium nach Karlsruhe zu verlegen, mit der Begründung, dass die Nähe beider Direktorien zu den badischen Musterfabriken in Ettlingen und Waghäusl die Entscheidungen der Zuckergesellschaften nur positiv beeinflussen könne. Freilich war dies eine eher fadenscheinige Begründung. Denn die Entscheidungen konnten nun nicht mehr von der württembergischen Zuckergesellschaft autonom getroffen werden, was sich beispielsweise bei der Beschaffung der Maschinen und Apparaturen nachteilig auswirkte und schließlich für Verzögerungen bei der Betriebsaufnahme in Züttlingen und Altshausen mitverantwortlich ist. Die württembergischen Aktionäre wollten bei der Maschinenbestellung eben auch württembergische Werkstätten be-

${ }^{65}$ StAL Bü 87 II Bü 844 (Brief des Freiherr Fr. von Ellrichshausen an seinen Bruder Ernst [in Stuttgart] vom 3. Mai 1838).

${ }^{66}$ StAL B 87 II Bü 844 (Dankschreiben des Staatssekretärs von Vellnagel im Namen des Königs an den Rittmeister und Adjutanten Freiherrn Ernst von Ellrichshausen, datiert Stuttgart, 4. Sept. 1838). 
rücksichtigt wissen, weil diese ihrer Meinung nach wohlfeiler liefern konnten. In dieser Hinsicht hatten die württembergischen Mechaniker freilich noch zu geringe Erfahrungen, um gut funktionierende technische Apparaturen und Maschinen fertigen zu können.

Hier gilt es, eine Bemerkung zum Entwicklungsstand des Schützenbach'schen Verfahrens einzufügen. Wie alle anderen Verfahren auch, war das Schützenbach'sche Verfahren genauso wenig ausreichend erprobt worden, sodass laufend Anpassungen und Verbesserungen vorgenommen werden mussten. Noch bevor der Betrieb in Züttlingen so richtig in Gang kam, gab es daher bereits erhebliche Zweifel ${ }^{67}$, ob die versprochenen Leistungen auch wirklich erreicht würden und der Preis des Rohzuckers pro Pfund tatsächlich unter jenem des importierten Kolonialzuckers liegen werde. Ein Aktionär, der sich namentlich nicht zu erkennen gab, veröffentlichte eine kritische Schrift zur Generalversammlung am 17. Februar $1838^{68}$. Der Kritiker knüpfte an die sich teilweise widersprechende Berichterstattung im Schwäbischen Merkur und im Deutschen Courier an und hielt der württembergischen Zuckergesellschaft vor, dass in Ettlingen bisher nur geringe Rübenmengen zur Zuckerraffination verarbeitet worden waren und die erzielten Ergebnisse von den in Aussicht gestellten Leistungen noch weit entfernt seien ${ }^{69}$. Bevor in dieser Hinsicht nicht mehr geschehe, solle man abwarten, bis die im Bau befindliche $\mathrm{Zu}$ ckerfabrik in Waghäusl eine wesentlich größere Rübenquantität verarbeitet habe und dann endlich vergleichbare Ergebnisse vorlägen.

Auch der von Schützenbach gescholtene Altshauser Fabrikdirektor Schmidt, der im Auftrag der württembergischen Zuckergesellschaft im April 1838 sich eine eigene Anschauung in Ettlingen machte, beurteilte die Ergebnisse der „badischen Methode" kritisch und verglich sie mit jenen des böhmischen Verfahrens, welches aber - wie erwähnt - eine Fortentwicklung französischer Techniken darstellte ${ }^{70}$. Schmidt rechnete Aufwand und Ertrag bei beiden Verfahren genau vor und meinte zusammenfassend, dass wenn auch die bis jetzt in Ettlingen erhaltenen Durchschnittsresultate das Maas der laut gewordenen Anpreisungen um ein Nabmbaftes

67 Siehe die Notiz in Wochenblatt (wie Anm. 15) 4 (1837) Nr. 13 vom 1. April 1837 S. 52, in der Zweifel geäußert werden, dass die Schützenbachische Methode kaum mehr als 6 Prozent Rohzucker bringen werde, also nicht mehr als die französische Methode, welche aber insgesamt einen billigeren Zucker „darstelle“.

68 Über die württembergische Zucker-Fabrikation aus Runkelrüben. Stuttgart 1838. Hinter dem Anonym darf man den Stuttgarter Kommerzienrat Jobst vermuten, der auf seiner Reise nach Holland und England 1837 in London eine Runkelrübenzuckerfabrik besichtigt hatte und sie vorbildlich eingerichtet fand; er empfahl die englische Macerationsmaschine in Württemberg nachzubauen; Wochenblatt (wie Anm. 15) 5 (1838) Nr.35 vom 1. September S. 161-164.

${ }^{69}$ Dazu heißt es in einem Bericht über die Generalversammlung der württembergischen Zuckergesellschaft am 17. Februar 1838, dass in Züttlingen bisher nur eine Ausbeute an Rohzucker von 7 Prozent erzielt worden sei und das Pfund Rohzucker Kosten rund 8 1/2 xr verursacht habe.

70 StAL B 87 II Bü 844 (datiert Altshausen, 29. April 1838). 
verringern, so geben sie doch die Beruhigung, daß das Schützenbach'sche Verfabren zur Zeit seines Beginnens, wirklich vortheilhafter ist, als die "französische" Metho$d e^{71}$. Der leichte Vorteil, den die Schützenbach'sche Methode bisher gewährte, könne noch gesteigert werden, wenn bei der Heizung Verbesserungen vorgenommen würden. Denn der Einsatz an Steinkohle und hartem Brennholz war immens, sodass in dieser Beziehung Korrekturen vorgenommen werden mussten.

In Altshausen erwarb die württembergische Zuckergesellschaft von der königlichen Hofkammer eine baufällige Mühle mit dazugehörigen Gütern im Umfang von rund 10 Morgen. Unter Leitung des Direktors Friedrich Schmidt, den bald der Ravensburger Bauinspektor Büchler ablöste, wurden im Laufe des Jahres 1838 zwei große Gebäude, ein Trocknungshaus und ein Siedhaus, errichtet und das Wasserrad am Trocknungshaus so angebracht, dass die Wasserkraft mit Hilfe einer Transmission auch in das Siedhaus übertragen werden konnte. Ein Torfschopfen in Altshausen wurde für die im Dornacher Ried gestochenen Torfplacken (Kapazität: 1 Mio. Stück) errichtet. Darüber hinaus wurde 1839 mit einem Waldseer Bürger ein Lieferungsakkord über je 5 Mio. Stück Torf für die Dauer von drei Jahren abgeschlossen. Die Versorgung mit Brennmaterial stellte sich in Altshausen also günstiger dar als in Züttlingen, wo auch teure Steinkohle aus dem Saarland verfeuert wurde. Indessen war man in Altshausen beim Bau der Fabrik in Rückstand geraten, sodass das Trocknen der Runkelrüben in Altshausen zunächst nur in zwei Öfen begonnen werden konnte; die fehlenden sechs Öfen trafen erst im Februar 1839 ein. Ebenso mangelte es im Siedhaus zunächst an den entsprechenden Maschinen und Gerätschaften, die ebenfalls erst im Frühjahr 1839 aufgestellt wurden. Maschinen und Geräte sollten von der Karlsruher Maschinenbau-Anstalt Kessler und Martiensen hergestellt werden, geliefert aber wurden sie schließlich von der Pariser Firma Louvrier Gaspard ${ }^{72}$. Nicht zuletzt deshalb konnte der Produktionsbetrieb nicht wie geplant im Winterhalbjahr 1838/39 aufgenommen werden, zum großen Ärger der Runkelrübenbauern aus der Umgebung. Die Rübenanbauer blieben auf ihrer Ernte sitzen.

Der Hofkameralverwalter Vogel, der sich zugunsten der Altshauser Zuckerfabrik eingesetzt hatte, wurde bloßgestellt, was Folgen für die nächsten Anbaujahre hatte ${ }^{73}$. Weigerten sich doch nun viele Akkordanten, Runkelrüben für die Altshauser Fabrik anzubauen. Statt der erhofften 10.000 Zentner wurden daher 1838 bloß 2.500 Zentner angeliefert und verarbeitet ${ }^{74}$. Für das folgende Jahr (1839) blieb man

71 Wie Anm. 70 S. 1.

72 Notiz im Auszug des Rechenschaftsberichtes vom 11. Januar 1840, Archiv des Hauses Württemberg, Altshausen. Hofdomänenkammer Bü 335.

73 Alle Angaben aus dem gedruckten Vortrag an die General-Versammlung der Württembergischen Gesellschaft für Zucker-Fabrikation vom 30. November 1838.

${ }^{74}$ Gedruckte „Mitteilung der Direktion der Württembergischen Gesellschaft für Zuckerfabrikation an sämmtliche verehrliche Actionäre“, datiert Carlsruhe, 28. September 1839, gez. Vogelmann. 
zuversichtlich und hoffte in Altshausen 100.000 bis 120.000 Zentner grüne Rüben zu verarbeiten. Wie sich im Lauf des Jahres 1838 herausstellte, war dies Wunschdenken. Weil die Ergebnisse nicht den Erwartungen der Aktionäre entsprachen, führte dies dazu, dass bei der Generalversammlung am 30. November 1838 das gesamte Direktorium zurücktrat, sodass die Versammlung einen neuen Vorstand wählte ${ }^{75}$. Lapidar heißt es dazu in den Württembergischen Jahrbüchern von $1838^{76}$, dass die Hoffnung, die man auf die Schützenbach'sche Methode gesetzt hat, sich sehr gemindert (hat) und die Hitze, womit die Unternehmungen begonnen haben, hat sich wie zu erwarten war, sebr abgeküblt. Ein Jahr später notierte der Redakteur der Württembergischen Jahrbücher J.G.D. Memminger ${ }^{77}$ : Die Runkelrüben-Zuckerfabrikation, welcher sich einige Zeit hindurch der Spekulationsgeist im Weg der Actienunternehmungen zugewendet hatte, entspricht wenig den Erwartungen der Unternebmer; das Schuzenbachische Verfabren in Darstellung des Zuckerstoffs, von welchem ein so großer Umschwung erwartet wurde, hat zum wenigsten für die Anwendung im Großen sich nicht bewäbrt.

Welche Ursachen hierfür verantwortlich sind, entzieht sich einer präzisen Antwort. Wie meistens bei solchen Problemen, ist eine ganze Reihe von Faktoren dingfest zu machen. Zum einen häufen sich die Nachrichten über unstetige Rübenlieferungen infolge stark schwankender Abnahmepreise (wie oben für 1838 erwähnt). Deshalb versuchte die Centralstelle über die Oberämter Oberschwabens und die landwirtschaftlichen Bezirksvereine 1839, Landwirte zum Anbau von Runkelrüben zu ermuntern und lobte Prämien aus ${ }^{78}$. In Züttlingen hatte man nicht genügend Rüben wegen ungünstiger Witterung erhalten können. Im Einladungsschreiben für die Generalversammlung am 11. Januar 1840 deutete die Direktion der württembergischen Zuckergesellschaft an, dass die Rübenernte in Altshausen nicht den Erwartungen entsprochen habe und man nur mit einer mittleren Quantität rech$n e^{79}$. Gleichwohl blieb man zuversichtlich, da es der Direktion gelang, mit einem Privatmann einen Kontrakt für die Lieferung von Runkelrüben zu günstigen Preisen abzuschließen. Günstiger Preis bedeutet hier, dass der Zentner Rüben bei 24 bis 26 Kreuzer zu stehen kam, wie er 1838 und 1839 im Raum Heilbronn auch für die Zuckerfabrik Mosbach bezahlt wurde; in Züttlingen musste man aber 30 xr bezahlen, um an ausreichend Rüben zu kommen ${ }^{80}$. Bei dem unbekannten Privatmann

75 Protokoll der General-Versammlung der Württembergischen Gesellschaft für Zucker-Fabrikation vom Freitag den 30. November 1838 in Stuttgart (gedruckt).

${ }^{76}$ Jahrbücher (wie Anm. 1) 1838 (Stuttgart/Tübingen 1839) S. 28.

77 Jahrbücher (wie Anm.1) 1839 (Stuttgart/Tübingen 1840) S. 345.

78 HStAS E 146 Bü 6083 Unterfasz. 4 n. 1 (Note der Centralstelle des landwirtschaftlichen Vereins, an das Innenministerium und an die Direktion der württembergischen Gesellschaft für Zuckerfabrikation, datiert Stuttgart, 19. Januar 1839).

79 Archiv des Hauses Württemberg Altshausen. Hofdomänenkammer Bü 335 (datiert Karlsruhe 25. November 1838).

80 Vgl. die Landwirtschaftlichen Jahresberichte aus Württemberg für 1837, 1839 und 1842, in: Wochenblatt (wie Anm. 15) 4 (1837) S. 208.6 (1838) S. 259-260. 9 (1842) S. 274-275. 
dürfte es sich um den Schultheißen Eisele aus Ertingen handeln, der wegen seiner Bemühungen um den Rübenanbau von dem Ausschussvorsitzenden der Zuckergesellschaft, General-Lieutenant von Röder, mit einem Diplom ausgezeichnet wur$\mathrm{de}^{81}$. Überhaupt vertraute man für die nächsten Kampagnen wieder auf beständige Lieferungen, vor allem aus dem Raum Riedlingen-Saulgau, wo für 1840 mit einer Rübenernte von ca. 42.000 Zentner gerechnet wurde, eine Menge, die im Trocknungshaus in Altshausen nicht verarbeitet werden konnte. Dafür wurden weitere Trockenöfen benötigt. Die Gesellschaft für Zuckerfabrikation gab daher grünes Licht für den Bau eines Trocknungshauses in Ertingen ${ }^{82}$ und eines weiteren in Waldsee ${ }^{83}$.

Zum anderen sind es Unstimmigkeiten im Aufbau der Zuckerfabriken und Uneinigkeit unter den Aktionären, wie die Gelder einbezahlt und zur Zwischenfinanzierung angelegt sowie ausgegeben werden sollen. Diese Unstimmigkeiten führten dazu, dass die ersten bescheidenen Gewinne rasch aufgezehrt waren, sodass schon im Februar 1840 der Bankier Moritz von Haber König Wilhelm I. um eine Privataudienz bat, in der er ihn um ein Darlehen der Hofbank in Höhe von $200.000 \mathrm{fl}$ ersuchte, eine ziemlich hohe Summe, für die er als Sicherheit 400 Aktien der württembergischen Zuckergesellschaft, die zu 70 Prozent bezahlt seien, also $140.000 \mathrm{fl}$, als Pfand bot. Verzinst werden sollte das Darlehen mit vier Prozent pro Jahr ${ }^{84}$. Ein solcher Schritt zu Anfang des Jahres 1840, der auch nicht von der Generalversammlung abgesegnet worden war, überrascht und verrät, dass das Aktienkapital der Zuckergesellschaft aufgebraucht und keine liquiden Mittel für den Betrieb der Zuckerfabriken mehr vorhanden waren. Zudem bestanden massive Zweifel bei den Aktionären, ob die beiden Zuckerfabriken je die versprochenen Erträge liefern werden, sodass Haber eine Erörterung der Kreditaufnahme auf einer einzuberufenden Generalversammlung scheute. Deshalb hielten die Aktionäre die Einzahlung ihres vollen Kapitalanteils zurück, was natürlich den Auf- und Ausbau der Zuckerfabriken erheblich behinderte. Doch auch das Darlehen der königlichen Hofbank reichte nicht aus, um die Kosten in den Griff zu bekommen. Die Generalversammlung der württembergischen Zuckergesellschaft beschloss deshalb im

${ }^{81}$ Urkunde erhalten im Archiv des Hauses Württemberg Altshausen. Hofdomänenkammer Bü 335 n. 22.

${ }^{82} \mathrm{Vgl}$. Landwirthschaftlicher Jahresbericht aus Würtemberg vom Jahr 1841, in: Wochenblatt (wie Anm. 15) 8 (1841) S. 260.

${ }^{83}$ Verhandlungen in der General-Versammlung der Württembergischen Gesellschaft für Rübenzucker-Fabrikation am 11. Januar 1840. Karlsruhe 1840, hier Auszug aus dem Rechenschaftsbericht S.11; dieses Trocknungshaus wurde für drei Jahre (1839-42) gegen jährliche $1.000 \mathrm{fl}$ an den Kaufmann Kees in Waldsee vermietet, wobei sich die Zuckerfabrik in Altshausen zur Abnahme der getrockneten Rübenschnitze zum Festpreis von $4 \mathrm{fl} 40 x \mathrm{xr}$ je Zentner verpflichtete.

${ }^{84}$ Briefliche Mitteilung des Bankiers von Haber an den Staatsrat von Gärttner, datiert Stuttgart, 22. Februar 1840 (Archiv des Hauses Württemberg Altshausen. Hofdomänenkammer Bü 335 n.25). 
September 1840, ein Darlehen in Höhe von bis zu $300.000 \mathrm{fl}$ beim Bankhaus Jakob Friedrich Gontard und Söhne in Frankfurt/Main aufzunehmen ${ }^{85}$.

Trotz der Darlehen, die den Fortbetrieb der Zuckerfabriken ermöglichten, blieb die Skepsis über die richtigen Methoden der Zuckergewinnung bestehen. Verstärkt wurden die Zweifel durch die bereits im Herbst 1839 während der Versammlung der deutschen Land- und Forstwirte in Potsdam diskutierte Frage der günstigsten Zuckergewinnungsmethode. Damals wurden zwei Verfahren einander gegenübergestellt, zum einen das Verfahren des Herrn Doctor Reichenbach aus Blansko in Mähren, der auf Maceration der Rüben und Filtration des Rübensaftes setzte, zum anderen die Schützenbach'sche Methode ${ }^{86}$. Die „badische Methode“, wie im Norden Deutschlands das Verfahren von Schützenbach genannt wurde, fand indessen nicht die erhoffte große Zustimmung, weil die Zeit der Beobachtung der neuen Methode doch noch zu kurz (war), um aus dieser ein sicheres Urtheil abzuleiten ${ }^{87}$. Was aber schwerer wog, war der Vorwurf, dass in vielen Regionen die falsche Rübensorte zur Zuckergewinnung angebaut wurde. Die Weiße Schlesische Rübe enthalte höhere Zuckergehalte als die Rote oder Gelbe Runkelrübe. Solange nicht überall die Weiße Rübe als Rohstoff angebaut werde, sei alles Bemühen um eine rentable Zuckergewinnung vergeblich ${ }^{88}$.

Unbeirrt von dieser Kritik hielt man in Baden und Württemberg an der Gelben Runkelrübe fest. Freilich hatte man sich in Hohenheim doch so viel von der Kritik zu eigen gemacht, dass hier nun die Oberdorfer Gelbe und Rote Runkelrübe angebaut und zur Samengewinnung vermehrt wurde ${ }^{89}$. Sie besaß gute Eigenschaften bezüglich des Wachstums, wurde sehr groß, hatte weniger Wurzeln und ließ sich daher leichter ernten und reinigen. Der Zuckergehalt war nur unwesentlich höher als bei der gewöhnlichen Gelben Runkelrübe. In der Frage der zweckmäßigsten Runkelrübe blieb man in Württemberg indifferent, was auch damit zu tun hatte, dass der sofortigen Einführung der Weißen Schlesischen Rübe die ungenügende Belieferung und Versorgung mit Samen entgegenstand. 1844 veröffentlichte das Wochenblatt für Land- und Hauswirtschaft einen Bericht über eine neue Zuckerrübe aus Österreich ${ }^{90}$, in die der Verfasser große Hoffnungen setzte. Der Redak-

${ }^{85}$ Notiz im Gutachten des Hofdomänenrates Riecke vom 13.Oktober 1842; Archiv des Hauses Württemberg Altshausen. Hofdomänenkammer Bü 335 (Auszug aus dem Anlehen-Vertrag zwischen der Württembergischen Gesellschaft für Zuckerfabrikation und dem Bankhaus J.F. Gontard und Söhne in Frankfurt/Main, datiert 10./19. Sept. 1840).

${ }^{86}$ Amtlicher Bericht über die [3.] Versammlung deutscher Land- und Forstwirthe zu Potsdam im September 1839. Hg. von Alexander von Lengerke. Berlin 1840, S.60-61, 312, 320-322. - Ökonomische Neuigkeiten und Verhandlungen 65 (1843) S. 389/390.

87 Bericht (wie Anm. 86) S. 61.

${ }^{88}$ So der schlesische Fachmann Freiherr von Koppy aus Krayn; Bericht (wie Anm. 86) S. 320 .

${ }^{89}$ Landwirthschaftlicher Jahresbericht aus Würtemberg vom Jahr 1840, in: Wochenblatt (wie Anm. 15) 7 (1840) S. 257.

90 Wochenblatt (wie Anm. 15) 11 (1844) Nr. 8 vom 24. Februar 1844 S. 53-55. 
teur Prof. Riecke fügte jedoch in einer Fußnote an, dass das gegenwärtige Siechtum der Runkelrübenzuckerfabriken nicht in der fehlerhaften mechanischen Einrichtung oder den chemischen Operationen liege, sondern generell an der schlechten Beschaffenheit der Rüben und am unsachgemäßen Anbau. In Hohenheim, am Wirkungsort Rieckes, nahm man den Bericht aus dem Zollvereinsblatt zur Kenntnis, aber große Hoffnungen setzte man nicht in die österreichische Zuckerrübe und betrieb auch keine aktive Propaganda für sie.

Die Schwierigkeiten, die inzwischen aufgetreten waren, hingen auch nicht mit der Rübensorte allein zusammen, sondern mit den Versuchen der beiden württembergischen Zuckerrübenfabriken, die Ankaufpreise so niedrig wie möglich zu halten. Durch Druck auf die Erzeugerpreise glaubte die Direktion offenbar, die stetig steigenden Produktionskosten senken zu können. Sie gab den Bauern den erforderlichen Samen und schrieb ihnen in den Verträgen einen zu niedrigen Preis vor. Die Reaktion auf abgesenkte Erzeugerpreise erfolgte prompt. Die Bauern verweigerten den Anbau oder vernachlässigten die Anbauempfehlungen, sodass im nächsten Anbaujahr wieder höhere Preise gezahlt werden mussten.

Stark schwankende Rübenpreise sind stets Gift für einen kontinuierlichen Produktionsbetrieb. Sie schwächen das Vertrauen in die Verlässlichkeit des Abnehmers. So erhielt 1839 die Zuckerfabrik in Züttlingen nicht genügend Runkelrüben, weil die Bauern lieber ihre Rüben an die Zuckerfabrik in Gerlachsheim bei Mergentheim zum Preis von 36 xr/Zentner lieferten ${ }^{91}$. 1842 geriet auch die Altshauser Fabrik in eine ähnliche Zwickmühle. Die Bauern im südlichen Oberschwaben gaben ihre Rüben an die Fabrik im badischen Stockach, die 36 xr (statt 27 xr je Zentner in Altshausen) bezahlte. Hinzukam, dass der unregelmäßigen Zahlungen wegen die Bauern im Raum Riedlingen zweifelten, ob die Zuckerfabrik Altshausen jemals ihren Verbindlichkeiten nachkommen werde. In der Folgezeit schenkten immer weniger Bauern den Ankündigungen aus Altshausen Vertrauen ${ }^{92}$, sodass sich die Direktion nach einer Lösung umsah, welche auf lange Sicht den Bezug des benötigten Rohmaterials sicherte. Sie bestand in der vertraglichen Anbindung eines großen landwirtschaftlichen Gutes an die Zuckerfabrik, nämlich des königlichen Maierei-Guts Altshausen. Damit verlor der Zukauf von Runkelrüben aus dem Raum Riedlingen 1843 an Bedeutung ${ }^{93}$.

91 Landwirthschaftlicher Jahresbericht aus Würtemberg vom Jahr 1839, in: Wochenblatt (wie Anm. 15) 6 (1839) Nr. 52 vom 28. Dezember 1839 S. 260.

92 Landwirthschaftlicher Jahresbericht aus Würtemberg vom Jahr 1842, in: Wochenblatt (wie Anm.15) 9 (1842) Beilage Nr. 15 vom 31. Dezember 1842 S. 275.

${ }^{93}$ Landwirthschaftlicher Jahresbericht aus Würtemberg vom Jahr 1843, in: Wochenblatt (wie Anm. 15) 10 (1843) Nr. 52 vom 30. Dezember 1843 S. 271. 


\section{Krisenjahre}

Trotz aller Maßnahmen kam die württembergische Zuckergesellschaft nicht aus den roten Zahlen heraus. Ein Gutachten, das der Hofdomänenrat Christian Heinrich Riecke im Oktober 1842 über das Schuldenwesen der Württembergischen Gesellschaft für Zuckerfabrikation im Hinblick auf die Forderungen und nach Sicherung der Einlagen der Aktionäre stellte und das König Wilhelm I. zur Kenntnis nahm, zeigt, dass die Gesellschaft nach Abzug aller Vermögenswerte (Gebäude, Grundstück, Maschinen, Vorräte) mit über einer halben Million Gulden ${ }^{94}$ verschuldet war. Im Fall eines Konkurses hätte keiner der Aktionäre sein Kapital oder Teile davon zurückerhalten. Riecke machte auch deutlich, dass selbst der Verkauf der beiden Zuckerfabriken kaum die geschätzten Vermögenswerte erlösen würde. Der Erlös flösse allein in die Ablösung der Hauptschuld, nämlich des Darlehens des Bankhauses Gontard in Höhe von $300.000 \mathrm{fl}$ und würde dafür gar nicht ausreichen. Ferner führte Riecke aus, dass auch die Verpflichtungen aus den abgeschlossenen Liefer-Akkorden, die Arbeitslöhne und die Baukosten noch vor den Ansprüchen der Aktionäre befriedigt werden müssten. Er meinte und befürchtete, dass der Schuldenstand, so wie die Verhältnisse sich im Jabr 1840 einmal gestaltet hatten und den die Direktion mit dem besten Willen nicht mebr abzuwenden vermochte und welcher sich bei längerer Fortdauer eher noch verschlimmern, als bessern dürfte. Dies waren klare Worte und die ließen kaum eine Besserung in naher Zukunft erwarten.

Ein Ausstieg von einzelnen Aktionären war auch deshalb nicht möglich, weil die württembergische Gesellschaft für Zuckerfabrikation einen verbindlichen Vertrag mit dem Erfinder Schützenbach auf elf Jahre bis zum 31. August 1848 geschlossen hatte. In den Statuten $(\mathbb{5 2}$ ) war ein Ausstieg von Aktionären nur mit Zustimmung des Erfinders möglich. Direktion und Ausschuss hätten einen Rechtsbruch begangen, wenn sie die vorzeitige Auflösung beschlossen hätten. Alle Institutionen, die am Fortbestand der württembergischen Zuckergesellschaft interessiert waren, waren nun aufgefordert, nach Mitteln und Wegen zu suchen, wie die Zuckerfabrikation in Württemberg doch noch profitabel werden könnte.

Auch die Centralstelle des württembergischen landwirtschaftlichen Vereins wollte nichts unversucht lassen. Sie zog weitere Erkundigungen ein, vor allem interessierte sie sich für abweichende Verfahren und dafür, wie in anderen Ländern die Rübenzuckerfabrikation gehandhabt wurde. 1843 entsandte sie Professor Siemens aus Hohenheim deshalb zu einer Inspektionsreise nach Preußen und Böhmen ${ }^{95}$. Professor Siemens fand nicht überall auf seiner Besichtigungstour nach Nord-

94 Archiv des Hauses Württemberg Altshausen. Hofdomänenkammer Bü 335 n. 36 (mit Randnotiz „Von S. K. M. eingesehen am 15. Octbr. 42. G.; d.h. von Seiner Königlichen Majestät eingesehen (die Initiale „G“ ist aufzulösen in Gärttner).

${ }_{95}$ Bericht über eine Reise nach Norddeutschland und Böhmen im Herbst 1843. In: Correspondenzblatt (wie Anm. 3) 45/NF 25 (1844) S. 121-136. - Einiges über den gegenwärtigen 
deutschland „blühende“ Zuckerfabriken vor, eigentlich nur im Magdeburgischen, mit geschickten Arbeitern, die zumeist aus Hamburg stammten und dort schon das Raffineriegewerbe ausgeübt hatten. Ein weiterer Vorzug der Zuckerfabriken im Magdeburgischen wie überhaupt in Preußen war, dass zum einen der technische Standard durch die vielen Maschinenfabriken höher war als in Württemberg, zum andern der Fabrikbesitzer selbst den Betrieb leitete, zumeist einen erfahrenen Maschinenbaumeister an seiner Seite hatte und zudem die Zuckerrüben auf seinem eigenen Gut anbaute, sodass er bedarfsorientierte Entscheidungen treffen konnte. Die Antriebskraft für die Maschinen lieferten überall in Preußen Dampfmaschinen, wodurch ein kontinuierlicher Produktionsablauf ohne Unterbrechung durch zu geringe Wasserkraft oder fehlende tierische Arbeitskraft (Pferde- und Ochsengöpel) gewährleistet war. 1.000 Zentner Rüben konnten so innerhalb von 24 Stunden verarbeitet werden, das war doppelt so viel als in Waghäusl oder in Züttlingen. Siemens erfuhr in magdeburgischen Fabriken auch von einer Schützenbach'schen Methode der Reinigung des so genannten zweiten Produktes, mit der sich größere Zuckerkristalle aus dem Sirup ausfällen ließen. Offenbar eine Entdeckung, die in Württemberg übel aufgenommen wurde, weil Schützenbach sie nicht mitgeteilt hatte, und in der Folge rasch zu technischen Anpassungen zwang!

Anders die Lage in Böhmen! Dort bauten Landwirte die Rüben an und pressten den Saft auch aus. Den gewonnenen unsauberen Saft kochte man zu Sirup bis zu einem bestimmten Grad Baumé ${ }^{96}$ ein und verkaufte ihn dann an die eigentlichen Zuckerfabrikanten. Siemens notierte, dass allerdings bei dem ganzen Verfahren vor dem Abdampfen das Reinigen des Saftes vernachlässigt wurde und deshalb nur unbefriedigende Zuckerausbeuten zu erreichen waren. Wichtig für den Erfolg im Magdeburgischen schien aber auch die Behandlung und Verarbeitung der Rüben zu sein, die in Preußen anders gehandhabt wurde als in Württemberg. Hier wurden zum Zerkleinern der Rüben große Reibezylinder mit ganz engstehenden Schneideblättern benutzt, und der Brei wurde durch hydraulische Pressen ausgepresst. Man begnügte sich mit einem einmaligen Pressen des Rübenbreis, bei dem ca. achtzig Prozent des Rübensaftes gewonnen werden konnten. Den restlichen Saft beließ man in der Rübenmasse, die dann als Viehfutter diente.

Die gesammelten Erkenntnisse von Prof. Siemens' Inspektionsreise nach Preußen scheinen nur zögerlich in die Verbesserung des Produktionsprozesses in Württemberg eingeflossen zu sein. Denn auch in den Jahren 1843 und 1844 blieben die versprochenen Gewinne aus. Das Defizit wuchs um weitere $155.478 \mathrm{fl}$ auf fast $990.000 \mathrm{fl}^{97}$, hauptsächlich weil den Banken in Karlsruhe, Stuttgart und Frankfurt

Stand der Rübenzuckerfabrikation in Deutschland, von Professor Siemens in Hohenheim. In: Wochenblatt (wie Anm. 15) 11 (1844) S. 137-139 und 141-143.

${ }_{96}$ Grad zur Dichtebestimmung von Flüssigkeiten über den Auftrieb im Wasser.

97 Archiv des Hauses Württemberg Altshausen. Hofdomänenkammer Bü 335 (Abschrift von der Vermögens-Übersicht der Zucker-Fabriken Altshausen und Züttlingen, datiert 30. September 1844). 
für die gewährten Darlehen Provisionen und Zinsen (5\%) bezahlt werden mussten, aber auch weil, um die Aktionäre zu beruhigen, seit 1. Oktober 1842 fünf Prozent Zinsen auf die ausgegebenen Aktien gutgeschrieben wurden, mit der fatalen Folge, dass dadurch das eingezahlte Aktienkapital und der Betriebsfonds in der Substanz geschmälert wurden. Bei diesem hohen Schuldenstand hätte eigentlich der Konkurs der württembergischen Zuckergesellschaft erklärt werden müssen, was aber nicht geschah. Im Gegenteil! Die Banken gaben die Hoffnung nicht auf und spendierten weiter Geld, damit die Fabriken den Betrieb aufrechterhalten und Verbesserungen vornehmen konnten.

1845 wollte aber der König nicht mehr tatenlos zusehen und - wohl aufgeschreckt durch die Beinahe-Pleite des Bankhauses Haber und Söhne Ende $1844^{98}$-, verlangte er ein Gutachten, wie die Aktiengesellschaft aufgelöst werden könnte, ohne dass die Aktionäre ihr eingezahltes Kapital vollständig verlören ${ }^{99}$. Der Gutachter, der schon erwähnte Hofdomänenrat Riecke, übernahm erneut diese Aufgabe und legte am 25 . Juli 1845 das verlangte Gutachten ${ }^{100}$ vor. Er erinnerte daran, dass eine Auflösung der Aktiengesellschaft nach den Statuten nur von einer Generalversammlung mit zwei Drittel-Mehrheit ein Jahr vor Ablauf des mit Schützenbach geschlossenen Vertrags beschlossen werden könne, d.h. spätestens am 31. August 1847 hätten zwei Drittel aller Aktionäre einer Liquidation der Zuckergesellschaft zustimmen müssen, um zu verhindern, dass die automatische Verlängerung des Gesellschaftsvertrags um weitere elf Jahre eintrete. Angesichts des Übergewichts der badischen und sonstigen nicht-württembergischen Großaktionäre (Bankhäuser Haber, Gontard, Lindheimer und Littauer, Großherzogin Stephanie von Baden, die Markgrafen Wilhelm und Maximilian von Baden, die freiherrliche Familie von Ellrichshausen ${ }^{101}$ ) ein ziemlich aussichtsloses Unterfangen. Riecke schloss sein Gutachten mit der wenig tröstlichen Aussicht, dass sich vorerst nichts ändern werde. Er meinte: Obschon nicht zu hoffen ist, daß in zwei Jahren sich diese Verbältnisse irgend wesentlich bessern sollten, so haben doch auch die Aktionäre kein Interesse dabei, die unvermeidliche Krisis von ibrer Seite zu beschleunigen; dieselben werden sich vielmehr, da die Sache nach dieser Zeit jedenfalls von selbst zur Entscheidung kommen müsse, alle weiteren Schritte darin vorerst füglich ersparen können ${ }^{102}$.

${ }_{98}$ Das Bankhaus Haber konnte nur durch einen Amortisationskredit der badischen Staatskasse vor dem Bankrott bewahrt werden.

${ }_{99}$ Archiv des Hauses Württemberg Altshausen. Hofdomänenkammer Bü 335 n. 37 (datiert 19. Juli 1845).

100 Archiv des Hauses Württemberg, Altshausen. Hofdomänenkammer Bü 335 n. 40 (datiert Stuttgart, 25. Juli 1845).

101 Ein handschriftliches Aktionärsverzeichnis vom 1. Januar 1841 weist allein den genannten Personen einen Anteil von 613 Stimmen (= 43\%) zu, gegenüber den in Streubesitz befindlichen württembergischen Aktien (Archiv des Hauses Württemberg Altshausen. Hofdomänenkammer Bü 335).

102 Wie Anm. 101. 
Dieses Gutachten legte der Dirigent der Centralstelle des landwirtschaftlichen Vereins, der Hofdomänenkammer-Direktor Ergenzinger ${ }^{103}$, umgehend dem König vor und dieser befahl die Einberufung einer Generalversammlung. Ergenzinger unterrichtete davon die Direktion der württembergischen Zuckergesellschaft ${ }^{104}$ und diese sah sich nach längerer Zeit (angeblich hatte es seit 1840 keine ordentlichen Generalversammlungen mehr gegeben) genötigt, eine Generalversammlung aller Aktionäre einzuberufen.

\section{Zusammenbruch und Vergleich (1848/49)}

Bei dieser Versammlung wurden offensichtlich die württembergischen Aktionäre, die auf eine Liquidation drängten, überstimmt. Die Befürworter einer Fortsetzung der Zuckergesellschaft wiesen darauf hin, dass den Schulden immerhin ein beachtlicher Aktivposten an Immobilien, Einrichtungsgegenständen und Vorräten gegenüberstand, sodass die Hoffnung nicht unbegründet sei, in den nächsten Jahren Gewinne zu machen und die Schulden nach und nach reduzieren zu können.

Der Zusammenbruch kam dann doch überraschend und anders, nämlich weil sich die allgemeine Wirtschafts- und Finanzkrise in Europa zuspitzte. Da war die Entscheidung von König Wilhelm I. Anfang November 1847, seine Aktien zu verkaufen, nur eine Randereignis. Der Monarch wollte nämlich aus zuverlässiger Quelle erfahren haben, dass die letzte Produktionskampagne wiederum kein halbwegs erträgliches Resultat gewährt habe, sodass er nun einen Schlussstrich ziehen wollte. Er wies den Hofdomänenkammer-Direktor an, seine achtzig Aktien öffentlich an der Börse in Frankfurt/Main versteigern zu lassen und eine Generalversammlung der Württembergischen Zuckergesellschaft noch vor Jahresende einzuberufen. Der König fühlte sich zu diesem Schritt veranlasst, weil durch den gänzlichen und öffentlichen Rücktritt von der Sache jede etwaige Illusion bei denjenigen zu zerstreuen (ist), die bisher noch in der Theilnabme Sr. Königlichen Majestät eine Bürgschaft dafür sehen zu können geglaubt haben, daß das Unternehmen noch auf irgendeiner soliden Grundlage betrieben werde und nicht so hoffnungslos sey, als jetzt für jedermann am Tage liege. ${ }^{105}$

Ergenzinger wollte zuvor noch den Rat des Bankiers Louis von Haber einholen und fragte an, ob er nicht einen Weg wisse, wie die öffentliche Versteigerung der

103 Ludwig Ernst (von) Ergenzinger (1795-1877) war am 9. Oktober 1844 zum Dirigenten der Centralstelle des landwirtschaftlichen Vereins ernannt worden; am 13. Juli 1847 wurde er jedoch aus seinem Amt entlassen; sein Nachfolger wurde Johann (von) Sautter.

104 Randnotizen auf Blatt 1 des Gutachtens von Hofdomänenrat Riecke, mit Unterschrift „Ergenzinger“ und Namensparaffe „der Hofd.Dir. Erg.“ und Datum 26. und 28. Juli 1845.

105 Archiv des Hauses Württemberg Altshausen. Hofdomänenkammer Bü 335 n. 51 (Schreiben der Hofdomänenkammer-Direktors Ergenzinger an Herrn Bergmeister von Haber in Carlsruhe, datiert Stuttgart, 29. November 1847). 
königlichen Aktien vermieden werden könne. Ergenzinger hoffte, dass Haber die achtzig Aktien erwerben werde, aber er täuschte sich. Haber sah keine Möglichkeit und bat dringend, den König von seinem Schritt abzubringen ${ }^{106}$. Er meinte, der König müsse im Fall einer Versteigerung seiner Aktien mit einem Verlust von vielleicht 95 Prozent rechnen, d.h. statt 40.000 hätte er bestenfalls nur $2.500 \mathrm{fl}$ erlösen können, insgesamt ein herber Verlust, der kein gutes Licht auf den finanziellen Zustand der württembergischen Zuckergesellschaft warf. An der Frankfurter Börse stellten die Aktien der württembergischen Zuckergesellschaft Ramschpapiere dar. Offenbar war der Entschluss des Königs, die Zuckergesellschaft zu verlassen, unverrückbar geworden. Der Geheime Legationsrat von Maucler, der den Staatssekretär vertrat, schrieb dem Hofkammer-Direktor Ergenzinger deshalb vertraulich, der König wolle bei der Generalversammlung am 20. Dezember 1847 eine Erklärung abgeben, und zwar solle Ergenzinger mitteilen, daß er (der König) mit der bisherigen Geschäftsfübrung höchst unzufrieden ist, und nicht länger bei der Gesellschaft beteiligt sein wolle ${ }^{107}$.

Was bei der Generalversammlung der württembergischen Zuckergesellschaft am 20. Dezember 1847 im Oberen Saal des Museums in Stuttgart beschlossen wurde, ist in den Akten nicht überliefert. Vermutlich ist der Schritt des Königs an den Bankplätzen in Europa aufmerksam registriert worden, ob er aber zum Zusammenbruch der beiden Bankhäuser Haber und Gontard am Jahresende 1847, als sie zahlungsunfähig wurden, und zwar infolge Kündigung der Kredite durch das Bankhaus Rothschild in Frankfurt/Main, entscheidend beitrug, ist doch sehr zweifelhaft. Denn die Lage auf den europäischen Finanzmärkten war das ganze Jahr 1847 über schon angespannt, sodass die Banken bei Geldgeschäften sich sehr zurückhielten und mehr und mehr misstrauten. In einem vertraulichen Schreiben des F.H. Stern an Hofrat Rudolf Kaulla, dem Mitteilhaber der württembergischen Hofbank, ist festgehalten, dass Rothschild schon seit drei bis vier Tagen eine Unlust an Geschäften zeigte, welche eine schwüle Luft auf unserm Platz verbreitete und vielfache Vermuthungen hervorrief, allein kein Mensch wußte die wirkliche Ursache, obgleich man gestern früh auch sagte, v. Haber sey ins Stocken gerathen, dieselben zablten jedoch noch fort und sollen gestern noch $130.000 \mathrm{fl}$ ausbezablt baben ${ }^{108}$.

Mit dem Entzug der Kreditwürdigkeit durch das Bankhaus Rothschild in Frankfurt/Main gerieten alle Unternehmen der Banken Haber und Gontard in Gefahr. In Baden waren wegen des starken Engagements des Bankhauses Haber die so genannten Drei Fabriken Badens betroffen: die Ettlinger Baumwollspinne-

106 Archiv des Hauses Württemberg Altshausen. Hofdomänenkammer Bü 335 n. 52 (datiert, Carlsruhe, 4. Dezember 1847).

107 Archiv des Hauses Württemberg Altshausen. Hofdomänenkammer Bü 335 n. 56 (datiert Stuttgart, 9. Dezember 1847).

108 Archiv des Hauses Württemberg Altshausen. Hofdomänenkammer Bü 335 n. 59 (Auszug aus dem Schreiben, datiert Frankfurt, 28. Dezember 1847). 
rei, die Zuckerfabrik Waghäusl und die Maschinenfabrik Kessler in Karlsruhe; in Württemberg natürlich wegen des Anlehens der Bank Gontard in Höhe von $300.000 \mathrm{fl}$ die Zuckergesellschaft mit ihren Fabriken in Züttlingen und Altshausen.

Die großherzoglich badische Regierung reagierte schnell auf einen entsprechenden Antrag der badischen Fabriken um Unterstützung, und noch am 30. Dezember 1847 war man im Staatsministerium in Karlsruhe übereingekommen, den drei Unternehmen mit einem Überbrückungskredit von 1,5 Mio. Gulden zu helfen ${ }^{109}$. Die Regierung setzte sofort eine Kommission ein, die prüfen sollte, ob es eine Chance für die Rettung der drei Unternehmen gäbe. Sie wollte verhindern, dass durch eine zeitgleiche Liquidierung dreier großer Firmen mehrere Hundert Arbeiter entlassen würden und ihre Familien ohne Einkommen blieben. Die soziale Lage sollte sich in der badischen Residenzstadt und ihrer Umgebung nicht weiter zuspitzen, war sie doch durch die wirtschaftliche Depression seit 1845 infolge ungenügender Ernten und stagnierender gewerblicher Entwicklung eh schon angespannt. Die beiden Kammern des badischen Landtags stimmten dem Vorschlag der Kommission, eine Zinsgarantie aus der Staatskasse für Anleihen der drei Fabriken $\mathrm{zu}$ geben $^{110}$, zu. Die Rede war von Anleihen von bis zu fünf Millionen Gulden ${ }^{111}$.

Die Nachricht vom Zusammenbruch der Bankhäuser Haber und Gontard erreichte blitzschnell natürlich auch Württemberg. Vor allem in den betroffenen Regionen Heilbronn und Oberschwaben machten sich sofort Befürchtungen breit, dass mit dem möglichen Konkurs der württembergischen Zuckergesellschaft auch das Ende der Zuckerfabriken drohe. Noch in der zweiten Januarwoche 1848 reagierte der Gemeinderat von Altshausen und legte die wirtschaftliche und soziale Situation der Gemeinde dar, wobei er die große Bedeutung der Zuckerfabrik als Arbeitgeber für Altshausen und dessen Umland hervorhob ${ }^{112}$. Von den 238 Familien würden im Fall eines Konkurses 57 Familien, d.h. etwa ein Viertel der Einwohnerschaft, ihren Lebensunterhalt verlieren, vor allem im Winter, wo es sonst anderweitig keine Arbeit gäbe. Im Rübenanbau fänden während des Sommers gut

109 Archiv des Hauses Württemberg Altshausen. Hofdomänenkammer Bü 335 n. 60 (Auszug eines Schreibens von Fr. Kusel in Carlsruhe vom 30. Dezember 1847 an Hofrat Kaulla); die Summe erschien König Wilhelm I. so irreal, dass er einen Schreibfehler vermutete und anmerkte, dass es sich wohl um eine Null zu viel handele, also nicht um $1.500 .000 \mathrm{fl}$, sondern nur um $150.000 \mathrm{fl}$ ging; zum politischen Hintergrund vgl. Paul Nolte: Gemeindebürgertum und Liberalismus in Baden 1800-1850 (Kritische Studien zur Geschichtswissenschaft 102). Göttingen 1994. S. 285-301. Bes. S.289-291.

110 Friedrich von Weech: Karlsruhe. Geschichte der Stadt und ihrer Verwaltung. Bd.II (1830-1852). Karlsruher 1898. S. 143-144.

111 Vgl. die Darstellungen im Schwäbischen Merkur vom Januar 1848, wo ausführlich über die Debatten in der Zweiten Kammer des badischen Landtags berichtet wurde; tatsächlich wurde eine Kreditaufnahme aller Unternehmen von insgesamt 4,9 Mio. fl (Laufzeit bis zu 15 Jahre, Zinssatz $3 \frac{1 / 2}{\%}$ ) bewilligt.

${ }^{112}$ HStAS E 146 Bü 6083 Unterfasz. 4 n.3 (Bericht der Regierung des Donaukreises an den Innenminister, datiert Ulm, 14. Januar 1848, mit Beilage des Gesuchs der Gemeinde Altshausen vom 8. Januar 1848). 
200 Personen Arbeit, das Trocknen der Rüben erfordere im Winter drei Monate lang rund 110 Arbeiter, ganz abgesehen davon, dass die Zuckerfabrik vielen Bauern durch Rüben- und Torffuhren einen guten Nebenverdienst biete. Der Gemeinderat unterstützte daher das Gesuch des Fabrikverwalters Krafft um eine zeitweilige Unterstützung aus der Staatskasse. Die Rede war von $150.000 \mathrm{fl}$, die notwendig wären, um eine Katastrophe abzuwenden ${ }^{113}$.

In Stuttgart nahm man diese Bitte um staatliche Unterstützung zur Kenntnis, sah aber keinen Handlungsbedarf. Der Finanzminister von Gärttner schrieb seinem Kollegen, dem Innenminister Schlayer, dass es sehr zweifelhaft sei, ob wegen des hohen Schuldenstandes von 1,7 Mio. Gulden die Zuckerfabrikation in Württemberg überhaupt aufrecht zu erhalten sei. Würde man helfen, käme diese Hilfe nicht dem hier noch fast unbedeutenden Industriezweig, sondern der Kreditwirtschaft zugute ${ }^{114}$. Er meinte zudem, dass in Württemberg die Fabriken, abgesehen von den ungeheuren Mißgriffen und unentschuldbaren Schwindeleien, welche begangen wurden, mit der Ungunst der Holzpreise und der Agrikulturverhältnisse zu kämpfen hatten.

Mit Blick auf den Charakter der württembergischen Zuckergesellschaft als Zusammenschluss privater Kapitaleigner, wollte die württembergische Regierung keine voreiligen Schritte unternehmen und sah zuerst die Eigentümer, d. h. die Aktionäre und Schuldner der Gesellschaft, in der Pflicht. Um die Liquidation der Zuckergesellschaft zu verhindern, ersuchten darum Direktion und Ausschuss offiziell um einen verzinslichen, gerichtlich gesicherten Kredit zur Fortführung des Betriebs in Altshausen und Züttlingen ${ }^{115}$. Die Unterzeichner des Gesuchs begründeten ihre Bitte zunächst mit dem Hinweis, dass das Stadtgericht Stuttgart schon eine gerichtliche Untersuchung angeordnet habe, und dass der hohe Schuldenstand dadurch zustande gekommen sei, weil seit 1840 der Betrieb der beiden Zuckerfabriken nur durch Zuschüsse der beiden Bankhäuser Haber und Gontard habe gewährleistet werden können. Man habe mehrere ungünstige Kampagnen in Folge gehabt, teils wegen ungenügender Rübenernten, teils weil man nach Maßgabe des Fortschritts der Zuckerfabrikation ständig neue Einrichtungen habe anschaffen müssen, sodass der Schuldenstand am 31. Dezember 1847 schließlich auf rund 1,74 Mio. Gulden angewachsen sei. Sie führten weiter aus, dass die Schuldenliquidation der Bankhäuser Haber und Gontard in Baden habe außergerichtlich geregelt werden können, in Württemberg sei zur Wahrung der Rechte der Gläubiger aber eine gerichtliche Einigung erforderlich, und zu diesem Zweck habe das Stadtgericht Stuttgart bereits eine Gläubigerversammlung einberufen lassen, die demnächst stattfinde. Die Unterzeichner führten weiter aus, dass die Zuckerfabriken, in den-

113 HStAS E 146 Bü 6083 Unterfasz. 4 n. 3 (Beilage ad 3, datiert Altshausen, 10. Januar 1848).

${ }^{114}$ HStAS E 146 Bü 6083 Unterfasz. 4 n. 5 (Note des Finanzministeriums an das Innenministerium, datiert Stuttgart, 10. Februar 1848).

115 HStAS E 146 Bü 6083 Unterfasz. 4 n. 6 (datiert Stuttgart, 13. Februar 1848). 
jenigen Orten und Regionen, wo sie errichtet worden seien, einen gewissen Wohlstand gebracht hätten. Würde nicht geholfen, erwüchsen große Nachteile für den Staat. Sie hätten die begründete Hoffnung, dass der Schuldenstand nach Abzug aller Vermögenswerte von Grund und Boden, Gebäuden sowie Inventar und Vorräten nicht so hoch sei, sodass eine gütliche Einigung mit den Aktionären und Gläubigern unmöglich werde. Die letzte Kampagne 1847/48 habe zudem einen Reinertrag von $137.000 \mathrm{fl}$ gebracht, welcher zur Reduzierung der Schulden ganz wesentlich beitrage. Sie versicherten, dass die beiden Zuckerfabriken in Altshausen und Züttlingen inzwischen genauso effizient wie jene in Waghäusl arbeiteten, deren Ergebnisse allgemein anerkannt werden. Die Untersuchungskommission ${ }^{116}$ werde gewiss genauso günstig urteilen, wie einer der größten Zuckerfabrikanten Norddeutschlands, der Unternehmer Ludwig Jacobs aus Staßfurt bei Magdeburg, der erst kürzlich die Zuckerfabrik in Altshausen besichtigt habe. Man sei sich da sehr sicher und zuversichtlich. Wenn jetzt durch den Bankrott der Bankhäuser der württembergischen Zuckergesellschaft die schwere Last der Zinszahlungen genommen sei, dann gehe es auch in Württemberg wieder aufwärts, so wie in Preußen und Norddeutschland, wo seit 1842 die Zuckerfabrikation sich mehr und mehr positiv entwickelt habe.

Die März-Ereignisse von 1848 und die sich anschließenden Unruhen beförderten die Abwicklung des gerichtlich angeordneten Konkurses nicht gerade. Die alten Minister wurden entlassen, die neuen Minister waren zu sehr mit den aktuellen Forderungen nach Aufhebung des Zehnten und der Grundlastenablösung beschäftigt, sodass Ministerien und Behörden nicht ganz so rasch reagierten als wie zuvor. Ein Schreiben der Masseverwaltung der Zuckergesellschaft an das Innenministerium vom 29. Mai 1848 macht dies deutlich. Darin erinnerte der Verwalter Wilhelm Heller, dass die Zuckergesellschaft inzwischen dem Gant unterworfen sei, sich also in der Liquidation befinde, und daher amtliche Gutachten über den Vermögens- und Schuldenstand der Zuckergesellschaft hätten erstellt werden müssen, worum man schon am 13. Februar und, weil nichts geschehen, erneut am 19. April gebeten habe, eine Bitte, welche bisher ohne Antwort geblieben sei. Falls das Ministerium sich nicht dazu berufen fühle, solle es die Bitte an die Zolldirektion überweisen, die mit den Verhältnissen bestens vertraut sei. Man wolle endlich Gewissheit haben, ob der Staat die Lebensfähigkeit der Fabriken gutachterlich feststelle. Am 20. Mai 1848 hatte das Stadtgericht Stuttgart den Gant über die Zuckergesellschaft erkannt und die Liquidationstagfahrt für den Juli angeordnet. Bis zu diesem Datum im Juli mussten die Gutachten vorliegen, um die Chancen eines Vergleichs zu wahren. Darum war Eile geboten. Offensichtlich kam nun Bewegung in die Gantsache und tatsächlich wurden unabhängige Gut-

$116 \mathrm{Zu}$ ihr gehörten der Abgeordnete Ökonomierat Theodor Mögling (Frank Raberg: Biographisches Handbuch der württembergischen Landtagsabgeordneten 1815-1933. Stuttgart 2001, S. 569-570), Professor Siemens aus Hohenheim und A. Ehrhardt, technischer Vorstand der Maschinenfabrik Eßlingen. 
achter bestellt: der Abgeordnete Ökonomierat Theodor Friedrich Mögling ${ }^{117}$, Professor Carl Siemens aus Hohenheim ${ }^{118}$ und August Ehrhardt, technischer Vorstand der Maschinenfabrik Esslingen. Alle drei besaßen keine Aktien der württembergischen Zuckergesellschaft, waren also formal wirklich unabhängige Gutachter. Als am 13./15. Juli 1848 der Vergleich gelang, welcher durch das Stadtgericht am 9. November 1848 genehmigt wurde, konnte vorerst die Fortführung des Betriebs beider Zuckerfabriken sichergestellt werden ${ }^{119}$.

Der Vergleich sah vor, dass die beiden Bankhäuser Haber und Gontard auf ihre Forderungen in Höhe von zusammen $558.700 \mathrm{fl}$ verzichteten und die Ansprüche der sonstigen Kreditoren in hundertprozentige Partialobligationen umgewandelt wurden. Zu diesem Zweck emittierte die württembergische Zuckergesellschaft Schuldbriefe zunächst im Gesamtwert von $336.100 \mathrm{ff}^{120}$. Später wurden weitere Schuldscheine ausgegeben. Dies bedeutet, dass die verbliebenen Gläubiger, darunter die württembergische Hofbank und die Bank Rothschild, ihre Forderungen in vorrangige Obligationen umwandelten, d. h. diese Forderungen mussten zuerst aus den Gewinnen getilgt werden, danach konnten alle anderen Gläubiger ihre Obligationen einlösen. Die Kredite der beiden Banken mussten zudem primär mit Zinszahlungen bedient werden. Erst danach durften die übrigen Gläubiger und die Aktionäre auf Zinsgutschriften hoffen. Akzeptieren mussten sämtliche Gläubiger freilich die Fortführung des Betriebs der Zuckerfabriken in Altshausen und Züttlingen und zwar solange, bis die Schulden der sogenannten Litt. B - Obligationen aus den Reinerträgen getilgt waren und sich das Betriebskapital nicht unter die Summe von $150.000 \mathrm{fl}$ vermindert hatte. Die $150.000 \mathrm{fl}$ wurden als erforderlicher Betriebsfonds zum Weitermachen angesehen. Die Summe orientierte sich am Mittelwert der letzten Kampagnen. Mit dem Vergleich vom 13./15. Juli 1848 wurde der Gant aufgehoben und die „Zuckergesellschaft in Liquidation“ durfte solange weitermachen, bis eine neue Gesellschaft gegründet würde. Eine Masseverwaltung trat jetzt offiziell an die Stelle der alten Direktion.

117 Mögling war von 1840 bis Mai 1848 Lehrer für Seidenraupenzucht in Hohenheim und im März zum Abgeordneten des Vorparlaments der Frankfurter Paulskirche gewählt worden; Raberg (wie Anm. 116) S. 572.

${ }^{118}$ Er war der erste Professor für Technologie in Hohenheim und kam 1838 von Hannover nach Württemberg, Günther Franz: Die Geschichte der Universität. In: Universität Hohenheim. Landwirtschaftliche Hochschule 1818-1968. Hg. von dems. Stuttgart 1968. S. 52.

119 Archiv des Hauses Württemberg Altshausen. Hofdomänenkammer Bü 335 n. 69 (gedruckter Vergleich). - HStAS E 146 Bü 6083 Unterfasz. 4 n. 12 (Bericht der Centralstelle für die Landwirthschaft an das Ministerium des Innern, datiert Stuttgart, 29. November 1850).

120 HStAS E 146 Bü 6083 Unterfasz. 4 n. 29 ad 29, datiert Stuttgart, 15. März 1849; genau waren 310 Schuldbriefe Litt A. à $1.000 \mathrm{fl}(=310.000 \mathrm{fl})$ und 261 Schuldbriefe Litt. B à $100 \mathrm{fl}$ $(=26.100 \mathrm{fl})$. 


\section{Schuldenschnitt und Neuanfang (1848-1854)}

Damit die Zuckerfabriken in Altshausen und Züttlingen künftig stabile Erträge erwirtschafteten, um die verbliebenen Verbindlichkeiten nach und nach abzutragen, musste ein neues Konzept gefunden werden. Angesichts der schwierigen politischen und wirtschaftlichen Situation von 1848/49 war dies kein leichtes Unterfangen. Umso mehr verwundert es, dass es tatsächlich der Masseverwaltung gelang, Gewinne zu erwirtschaften, die es vorher kaum gegeben hatte. 1848/49 betrug der Reingewinn $22.013 \mathrm{fl}, 1849 / 50$ waren es nur $15.487 \mathrm{fl}, 1850 / 51$ aber unglaubliche $101.941 \mathrm{fl}, 1851 / 52$ dann $58.219 \mathrm{fl}$, und so weiter, im Durchschnitt der Jahre 1848 bis 1854 rund $48.233 \mathrm{fl}$, eine deutliche Verbesserung gegenüber der Situation vor 1848, und dies trotz der Verdoppelung der Zuckersteuer im Jahr $1850^{121}$.

Die Hoffnung auf den Weiterbestand war also nicht unberechtigt. Zugleich erkannte die Verwaltung, dass die Einrichtungen der beiden Zuckerfabriken nicht optimal genutzt wurden. Die Züttlinger Fabrik besaß keine Raffinerie, um besser verkäuflichen Kristallzucker herstellen zu können. Dafür gab es keine Probleme beim Einkauf der benötigten Runkelrüben, die im Oberland für eine bessere Auslastung der Produktion von den Bauern nicht zur Verfügung gestellt wurden. Hier waren die Bauern mit den Ankaufspreisen unzufrieden, was den Fabrikverwalter Leidenfrost vor einige Herausforderungen stellte. Unter Mithilfe des Landwirtschaftlichen Bezirksvereins Saulgau versuchte er im Frühjahr 1852, die Bauern zum Rübenanbau zu überreden, aber offenbar mit wenig Erfolg ${ }^{122}$. Immerhin gelang es ihm im Juni 1852 aber, einen Vertrag mit dem Hofkameralamt Altshausen über die Pachtung der königlichen Domäne Arnetsreute abzuschließen, wo Runkelrüben auf rund 200 Morgen angebaut werden sollten ${ }^{123}$.

Vorstand und Hauptgläubiger der Zuckergesellschaft waren sich einig, dass trotz der Gewinne es sehr, sehr lange dauern würde, bis Mittel aus den Reinerträgen für Investitionen verfügbar würden. Fünfzehn, zwanzig, vielleicht auch dreißig und mehr Jahre waren ein Zeitraum, in dem es keine Möglichkeit gab, Investitionen von 10.000 und mehr Gulden vorzunehmen, ein Zustand, der rasch geändert werden

121 Nämlich von einem auf zwei Thaler im Zollvereinsgebiet; gegen diese Erhöhung der Zuckersteuer intervenierte der Landwirtschaftliche Bezirksverein Saulgau zugunsten der Zuckerfabrik Altshausen beim Innenminister; die Zentralstelle für die Landwirtschaft wurde vom Minister gebeten eine Stellungnahme abzugeben; HStAS E 146 Bü 6083 Unterfasz. 4 ohne Nummer, datiert Stuttgart, 29. November 1850.

122 Vgl. den Bericht über die Versammlung des landwirtschaftlichen Bezirksverein vom 18. April 1852 im Amts- und Intelligenzblatt für den Oberamtsbezirk Saulgau und die Umgegend Nr. 30 von Dienstag, 20. April 1852, S. 127-128 und die Anzeige des Altshauser Fabrikverwalter über Zuckerrüben-Accorde, datiert Altshausen, 13. April 1852 (ebd. S. 126).

${ }^{123}$ Archiv des Hauses Württemberg Altshausen. Hofdomänenkammer, Hofkameralamt Altshausen, Domäne Arnetsreute 3/25, n. 7 (die Hofdomänenkammer weist das Hofkameralamt Altshausen an, den Pachtvertrag mit der Zuckerfabrik Altshausen betreffend die Domäne Arnetsreute auszufertigen, datiert Stuttgart, 7. Juli 1852). 
musste, wenn die Zuckerfabriken nicht hinter die technische Entwicklung in anderen Ländern zurückfallen wollten. Ein Wandel konnte nur durch eine Abänderung des Gesellschaftsvertrags eintreten, wozu die Bestimmungen des Vergleichs vom 13./15. Juli 1848 überarbeitet werden mussten, was nichts anderes hieß, als dass der Schuldenberg durch einen Kapitalschnitt reduziert und neue Aktien ausgegeben werden mussten. Wie ein solcher Kapitalschnitt aussehen konnte, darüber wurde lange debattiert. Endlich einigte man sich. Nach einem Vorschlag des Frankfurter Bankiers Anselm Oppenheim ${ }^{124}$ sollte eine neue Gesellschaft mit einem Kapital von einer Million Gulden gegründet und ausgestattet werden; jede Aktie sollte wiederum $500 \mathrm{fl}$ kosten, aber das neue Aktienkapital sollte entsprechend den unterschiedlichen Anteilen der Gläubiger am Eigentum der alten Aktiengesellschaft aufgeteilt werden, und zwar in Aktien A im Gesamtwert von $850.000 \mathrm{fl}$ und Aktien B im Betrag von $150.000 \mathrm{fl}$. Entscheidend war aber, dass die Obligationsbesitzer B für ihr nominelles Kapital von 1,48 Mio. Gulden vierzig Prozent der neuen Aktien, also $592.000 \mathrm{fl}$ plus Zinsen für $2 \frac{1}{2}$ Jahre à 4 Prozent (= $148.000 \mathrm{fl}$ ), zusammen $740.000 \mathrm{fl}$ erhielten, die alten Aktionäre für ihr Kapital von $750.000 \mathrm{fl}$ aber nur 20 Prozent oder $150.000 \mathrm{fl}$, d.h. sie erlitten einen Verlust von achtzig Prozent. Nolens volens stimmten Gläubiger und Alt-Aktionäre diesem Vorschlag in der Generalversammlung am 27. Juli 1854 zu. Damit war ein Schlussstrich gezogen und ein Neuanfang unter der neuen und alten Firma „Württembergische Gesellschaft für Zucker-Fabrikation" möglich geworden.

Doch mit frischem Kapital war es nicht getan. Zusätzlich mussten Mittel und Wege gefunden werden, wie die Ertragsseite dauerhaft verbessert werden könnte. In den Protokollen finden sich wiederholt Vorschläge hierzu, von denen aber nur wenige eine Chance auf Verwirklichung hatten ${ }^{125}$. Aussicht auf Verwirklichung hatte eigentlich nur die Idee in Altshausen, die bisher kaum verwertete Melasse, welche überwiegend der Viehfütterung zugeführt wurde, als Grundstoff für eine Spiritusbrennerei zu verwenden. Die Alkoholdestillation (Spiritus) versprach gewinnbringend zu sein, und so wurde tatsächlich eine Brennerei in Altshausen ein-

124 Dieser besaß nach dem Verzeichnis vom 1. Januar 1841 fünf Aktien; der gedruckte Vorschlag von A. Oppenheim ist undatiert, sollte aber der Generalversammlung am 20. Juni 1854 zur Genehmigung vorgelegt werden; Archiv des Hauses Württemberg Altshausen. Hofdomänenkammer Bü 335.

${ }^{125}$ So schlug der Unternehmer und Bankier Haniel 1852 vor, die beiden württembergischen Zuckerfabriken in einer Art Kombinat zusammenzuschließen und den Rohzucker dort zu Kristallzucker raffinieren zu lassen, wo die besseren technischen Einrichtungen vorhanden waren (d.h. in Züttlingen) und in Altshausen, wo die Verarbeitungskapazität größer war als die angelieferte Rübenmenge getrocknete Rübenschnitze aus Züttlingen zu verarbeiten, die Rückstände beider Fabriken - hauptsächlich Melasse - an einem Ort zu Spiritus zu brennen; die Idee wurde wegen der zu erwartenden immensen Transportkosten verworfen; Archiv des Hauses Württemberg Altshausen. Hofdomänenkammer Bü 335 (Abschrift des Protokolls der Versammlung der Gläubiger und Aktionäre, datiert Stuttgart, 22. November 1852). 
gerichtet. Die zuckerfreien, ausgelaugten Schnitze ließen sich zudem zur Papierfabrikation gebrauchen. Diese faserigen Teile ergaben zwar kein feines Schreibpapier, aber als grobes Packpapier war es durchaus tauglich ${ }^{126}$. Ob diese Anregung umgesetzt wurde, geht aus den Akten leider nicht hervor. Geld verdienen ließ sich ferner mit dem Ascheverkauf zum Düngen der Felder. In Züttlingen wurde dies schon seit längerem praktiziert, doch entstanden wiederholt Streitigkeiten über den Preis mit den Abnehmern ${ }^{127}$.

\section{Verschlungene Wege des Wissens- und Technologietransfers}

Wie die bisherigen Ausführungen zeigen, waren an der Einführung der Fabrikation des Rübenzuckers in Württemberg als neuer landwirtschaftlicher Industrie hauptsächlich die Centralstelle des landwirtschaftlichen Vereins und das ihr unterstellte Land- und forstwirtschaftliche Institut in Hohenheim beteiligt. Die Mitglieder der Centralstelle, besonders der wissenschaftliche Sekretär Professor Plieninger (1795-1879) und der Staatsrat und Direktor des Königlichen Naturalienkabinetts, der ehemalige Tübinger Professor der Naturwissenschaften Carl Friedrich (von) Kielmeyer (1765-1844), erstellten die maßgeblichen Gutachten, auf deren Grundlage dem badischen Fabrikanten Carl Sebastian Schützenbach 1837 ein Einführungsprivileg für seine Methode der Runkelrübentrocknung und Zuckerextraktion in Württemberg erteilt wurde. Als dritte Institution muss die königliche Hofdomänenkammer mit dem ihr unterstellten Hofkameralamt Altshausen erwähnt werden. Letztlich verdankt die Zuckerfabrik in Altshausen ihre Entstehung den Hofdomänenkammerbeamten in Stuttgart und Altshausen. Diese sorgten auch wegen der Unlust der oberschwäbischen Bauern zum Rübenbau mit der Verpachtung der königlichen Domänen Arnetsreute (1853), Lichtenfeld (1857), Tiergarten (1860) und Zwirtemberg (1860) ${ }^{128}$ für eine sichere Rübenlieferung. Da die Hofdomänenkammer das private Vermögen des Königs verwaltete und nicht anzunehmen ist, dass die Hofkammerbeamten ohne Wissen und Zustimmung Wilhelms I. handelten, darf man in der Tätigkeit des Altshauser Hofkameralamtes auch mittelbar königliches Handeln erblicken. Dies erklärt auch, warum in den Akten von Entscheidungen der Ministerien des Innern und der Finanzen kaum die

\footnotetext{
126 Schon bei der kurzlebigen Ulmer Zuckerfabrik hatte man Versuche angestellt, aus den faserigen Resten Papier herzustellen; Wochenblatt (wie Anm.15) 4 (1837) Nr. 10 vom 11. März 1837 S. 40.

127 StAL B 87 II Bü 1321 (der Fabrikverwalter Köstlin weist das Angebot des Rentamtes der Freiherren von Ellrichshausen 2.000 Simri Asche für 10 Louisdor kaufen zu wollen zurück; er verlangte $3 \frac{1}{2} \mathrm{xr}$ pro Simri; datiert Züttlingen, 3. November 1841).

128 Eberhard Fritz: Die Hofdomänenkammer im Königreich Württemberg. In: ZWLG 56 (1997) S. 151.
} 
Rede ist. Regierung und Ministerien standen aber im Hintergrund bereit, wenn Hilfe erforderlich werden sollte.

Zwischen allen genannten Institutionen existierten personelle Verflechtungen. Aus der Hofdomänenkammer kamen die Präsidenten und Dirigenten der Centralstelle des landwirtschaftlichen Vereins, Gärttner und Ergenzinger. Viele Akteure gehörten zum Netzwerk der Centralstelle und des landwirtschaftlichen Vereins, wobei festzuhalten ist, dass niemand aus freien Stücken Mitglied der Centralstelle oder des landwirtschaftlichen Vereins werden konnte, sondern nur durch königliche Ernennung, zumeist auf Empfehlung des Präsidenten der Centralstelle.

Zum Netzwerk der Centralstelle darf mittelbar auch der Freiherr Friedrich von Ellrichshausen aus Assumstadt-Maisenhälden gerechnet werden, der über seine Brüder Ludwig und Ernst Gustav mit den Verhältnissen und Aufgaben der Centralstelle vertraut war. Über ihn lief die Verbindung nach Baden, wo er als Direktor des großherzoglichen badischen landwirtschaftlichen Vereins und Kammerherr Zugang zu Hofkreisen hatte. Er gab die Anregung, in Württemberg eine ähnlich strukturierte Aktiengesellschaft für die Zuckerfabrikation zu bilden, wobei er sich freilich exklusiv Rechte an dem vielgerühmten Schützenbach'schen Verfahren für sein Rittergut sicherte. Sein Bruder Ernst Gustav von Ellrichshausen, Rittmeister und Adjutant des Königs, selbst kein Mitglied der Centralstelle und des landwirtschaftlichen Vereins, gehörte anfangs der Direktion und dem Verwaltungsausschuss der Gesellschaft an, die die Investitionen zu genehmigen hatten ${ }^{129}$. In seiner Eigenschaft als Adjutant konnte er dem König beinahe täglich die neueste Entwicklung vortragen und ihn über auftretende Probleme und Schwierigkeiten unterrichten.

Die Einladung zur Bildung einer Aktiengesellschaft, der König Wilhelm I. mit der Zeichnung von achtzig Aktien schon am 20. April 1837 folgte, bedeutete gleichsam eine Garantie für die Solidität des Unternehmens, worauf hauptsächlich die Banken setzten. Wilhelm I. war nicht nur Aktionär der Zuckergesellschaft sondern auch mittelbar Initiator einer Zuckerfabrik in Oberschwaben. Der Kurator seines Privatvermögens, der Hofkammer-Direktor Karl (von) Gärttner (1788-1861), lotete in seinem Auftrag die Möglichkeiten einer Ansiedlung aus und empfahl dem König den Standort Altshausen. Als Gärttner am 29. März 1839 Präsident der Centralstelle wurde, dürfte er über die korrespondierenden Mitglieder des landwirtschaftlichen Vereins stets auf dem Laufenden bezüglich der Entwicklung der Zuckerfabrikation in Deutschland und Europa gehalten worden sein. Ihm ist es zu verdanken, dass ein weiterer Techniker nach Hohenheim berufen wurde. Siemens kam 1838 nach Hohenheim und wurde 1839 zum Professor und Inspektor der chemisch-technischen Werkstätten berufen. Ihn sandte Gärttner 1843 nach Magde-

${ }^{129}$ Er unterzeichnete zusammen mit anderen Personen als Mitglied der provisorischen Gesellschafts-Direktion den Vertrag mit Schützenbach, welcher der württembergischen Zuckergesellschaft das Patent sicherte (datiert Stuttgart, 20. April 1837). 
burg und Böhmen, wo dieser sich über die anders eingerichteten und erfolgreichen Zuckerfabriken unterrichten und Vorschläge zur Verbesserung des Rübenanbaus und der Zuckergewinnung in Württemberg machen sollte. Professor Siemens gehörte 1848 zu den Gutachtern, die über den Fortbestand der Zuckergesellschaft zu befinden hatten. Sein Votum dürfte nicht wenig zum Erhalt der Zuckerfabrikation in Württemberg beigetragen haben, ebenso wie jenes des ehemaligen Hohenheimer Ökonomierates Theodor Mögling.

Als Gärttner, der 1844 Finanzminister wurde, 1837 (damals in seiner Funktion als Hofdomänenkammer-Direktor) die Chancen für einen geeigneten Standort einer Zuckerfabrik in Oberschwaben auslotete, geschah dies zwar im Auftrag des Königs, der neben privaten Rücksichten vor allem von dem Motiv geleitet worden sein dürfte, eine neue landwirtschaftliche Industrie in einem aus Stuttgarter Sicht als rückständig geltenden Landesteil aufzubauen und Entwicklungsimpulse zu setzen $^{130}$. Die Zuckerfabrik in Altshausen bildete in der Raumordnungs- und Strukturpolitik des Königreichs einen ersten industriell-gewerblichen Kern in Oberschwaben, der - wie man an den Aufträgen für das Eisenhüttenwerk Wilhelmshütte in Schussenried ${ }^{131}$ erkennen kann (siehe unten) - tatsächlich die ihr zugedachte Aufgabe erfüllt hat. Beide Unternehmen - Zuckerfabrik und Wilhelmshütte - müssen als strukturpolitische Entwicklungsmaßnahmen Oberschwabens, die noch dazu beinahe gleichzeitig entstanden, verstanden werden, wobei Privatund Staatswirtschaft sich gegenseitig ergänzten.

Freilich verlief nicht alles nach Plan, wie ein in dieser Hinsicht aufschlussreicher Bericht ${ }^{132}$ aus den Anfangsjahren der Zuckergesellschaft lehrt. Er stammt vom Stuttgarter Kommerzienrat Friedrich Jobst ${ }^{133}$, der im Frühjahr 1837 nach Köln, Holland, London und Paris reiste, hauptsächlich in eigenen Geschäften, aber doch

130 Archiv des Hauses Württemberg Altshausen. Hofdomänenkammer, Hofkameralamt Altshausen, Domäne Lichtenfeld 3/31, vol.3, n. 2 (Schreiben des Hofdomänenkammer-Direktors Kohlhaas an das Hofkameralamt Altshausen wegen Verpachtung der Domäne Lichtenfeld, datiert Stuttgart 4. Februar 1823); die Hofdomänenkammer war der Ansicht, dass man einen gebildeten Landwirt für den Pacht suchen müsse, der theils in Beziebung auf die sichere Verbesserung jener Domänen, theils um hauptsächlich auf die Einwirkungen einer rationellen Landwirthschaft auf eine Gegend, wo die Landwirthschaft noch mancher Verbesserung bedarf (geeignet sei). - Die Beispiele lassen sich vermehren, z. B. als $1841 \mathrm{Graf}$ von Beroldingen in seiner Eigenschaft als Vorsitzender des Landwirtschaftlichen Bezirksvereins für das Allgäu sich über den Starrsinn seiner Landsleute beklagte; Correspondenzblatt (wie Anm. 3) 40/NF 20 (1841) S. 146. - Ähnlich 1841 der Rentmeister Wörz, Verwalter des Hospitalguts in Bärenweiler; ebd. S. 148/149, und Oberamtmann Johannes Friz von Biberach 1845; Correspondenzblatt (wie Anm. 3) 49/NF 29 (1846) S. 333.

131 Vgl. hierzu die Ausführungen von Uwe Flieganf: Die Schwäbischen Hüttenwerke zwischen Staats- und Privatwirtschaft. Zur Geschichte der Eisenverarbeitung in Württemberg (1803-1945) (Stuttgarter historische Studien 9). Ostfildern 2007. S. 56-58 und 237.

132 HStAS E 146 Bü 6086 (datiert Stuttgart, 6. Juli 1837).

133 Jobst war 1824 Mitglied der Zentralstelle des Handels- und Gewerbevereins und 1835 Mitglied des landwirtschaftlichen Vereins geworden. 
auch um Einblicke in neue, d.h. in Württemberg unbekannte, Fertigungsmethoden der Zuckergewinnung zu erhalten. Zu diesem Zeitpunkt war gerade die württembergische Zuckergesellschaft gegründet worden. Aus diesem umfangreichen Bericht seien ein paar für die Zuckergewinnung aus Runkelrüben bemerkenswerte Notizen mitgeteilt.

Jobst nahm den Weg rheinabwärts über Köln nach Rotterdam, wo er von den von Jahr zu Jahr wachsenden Importen von Rohzucker aus der holländischen Kolonie Java erfuhr. Dieser Rohzucker aus Zuckerrohr, allgemein nur Kolonialzucker genannt, wurde in Rotterdam und Amsterdam in eigens dafür erbauten Raffinerien in Kristallzucker verwandelt. Kolonialrohzucker aus Rotterdam wurde auch zum Raffinieren nach Köln gebracht. Von diesem Kolonialzucker brachte Jobst Proben nach Stuttgart mit. Jobst sah die Gefahr, die aus der Konkurrenz des Kolonialzuckers den Runkelrüben-Zuckerfabriken drohte. Nachdenklich notierte er: Nimmt fortwäbrend die Anplanzung des Zuckerrobrs in dem Maße zu, daß in 10 Jabren Java allein mehr als ganz Deutschland mit Zucker verseben könnte und fallen alsdann die Preise noch mehr, dann darf der Rübenzucker nicht auff 17 eigene Kosten kommen, wenn die Fabrikation desselben fortbesteben soll ${ }^{134}$.

In London suchte Jobst Kontakte zu der „United Kingdom Patent Betroot Sugar Association“ zu knüpfen, von der er wusste, dass sie Zuckerrüben aus der Grafschaft Essex verarbeitet hatte und ca. fünf Prozent Zucker extrahieren konnte. Doch auch hier stand der Betrieb still, aber immerhin gelang es ihm mit dem technischen Leiter Bensen, einem Hannoveraner, und dem Maschinenbauingenieur Brinjes, der die Londoner Zuckerfabrik mit Maschinen und Apparaten beliefert hatte, Gespräche zu führen. Sein Interesse galt den neuartigen mit Dampf und Dampfkraft betriebenen Vacuum-Evaporationspfannen und einem Macerator mit Expressionskammer, d.h. mit hydraulischer Presse, in welche ebenfalls Heißdampf eingeleitet wurde, Geräte, die in Württemberg unbekannt waren und von denen er Zeichnungen und Pläne zu erwerben suchte. Auch die stillstehende Zuckerfabrik $\mathrm{zu}$ besichtigen, blieb ihm verwehrt, da diese inzwischen an eine fremde Gesellschaft verkauft war, zu der Bensen keine Verbindung hatte.

Um an verlässliche Informationen zu gelangen schlug Jobst einen anderen Weg ein. Er lud Bensen ein, nach Württemberg zu kommen, wo sich gerade die Zucker-Aktiengesellschaft gebildet hatte und versprach ihm - natürlich unverbindlich - sich für ihn dort einzusetzen. Sie schieden voneinander mit dem Versprechen, die gewünschten technischen Beschreibungen und Pläne mitzuteilen und sich gegenseitig bei ihren Plänen zu unterstützen. Bensen war ein weit gereister Mann, der von seinen Gönnern nach dem holländischen Demeray in Guayana (Südamerika) gesandt worden war, um dort die Kunst der Raffination des Kristallzuckers aus dem Rohzucker des Zuckerrohrs zu studieren und sie nach England zu transferieren. Jobst vertraute den Angaben von Bensen vollkommen, nicht zuletzt weil dieser

134 HStAS E 146 Bü 6086 fol. 3v. 
zusammen mit dem Maschinenbauer Brinjes den Auftrag erhalten hatte, einen neuen Macerator für eine im Bau befindliche Zuckerfabrik in Belgien anzufertigen. Diese belgische Zuckerfabrik ginge im Spätjahr 1837 in Betrieb, hieß es. Bensen schlug vor, dass ein württembergischer Fachmann dort den Produktionsbetrieb kennenlerne. Zudem wollte er ihm eine Zeichnung dieses neuen Macerators zukommen lassen.

In Paris, wo Jobst ebenfalls Erkundigungen über den Stand der französischen Runkelrüben-Zuckerfabrikation einzog, erfuhr er, dass der badische Professor Walchner, der das Schützenbach'sche Verfahren begutachtet hatte, sich vor wenigen Wochen in der französischen Hauptstadt aufgehalten hatte, um bei dem Ingenieur Charles Derosne Maschinen und Apparate für die badische Zuckerfabrik einzukaufen. Die Fabrik von Derosne stand ihm zur Besichtigung offen; Derosne selbst war abwesend, sodass er sich nur eine grobe Anschauung von den neuartigen Apparaten machen konnte, die für eine böhmische Zuckerfabrik bestimmt waren. Kontakt nahm er aber zu dem Ingenieur Pecqueur auf, der einen ähnlichen Macerator konstruiert hatte wie der in englischen Diensten stehende Techniker Bensen. In Paris versuchte er auch von Leuten Auskünfte zu erhalten, vor allem darüber, was sie von dem Schützenbach'schen Verfahren hielten. Professor Walchner hatte dort die neue Methode der Rübentrocknung etlichen Fachleuten mitgeteilt, die anfangs zwar skeptisch waren, aber nicht ausschließen wollten, dass das Schützenbach'sche Verfahren nach einigen Verbesserungen die Krone aller Erfindungen in diesem Fache verdiene. Solange die Sache nicht ausreichend erprobt sei, sei das beste Verfahren, aus Runkelrüben Zucker zu gewinnen, immer noch dasjenige, aus frischen Rüben den zuckerhaltigen Saft vollkommen zu extrahieren, denn je länger die Rüben in Gruben aufbewahrt wurden, desto weniger zuckerhaltigen Saft enthielten sie. Dies war einhellige Meinung der französischen Fachleute. In dieser Auffassung wurde er auch vom Vice-Präsidenten der französischen Abgeordnetenkammer, Delessert, einem der größten Zuckerproduzenten Frankreichs, welcher zugleich einer der ersten war, der aus Runkelrüben Zucker fabrizieren ließ, bestätigt. Delessert riet allen, die gegenwärtig eine Zuckerfabrik errichten wollten, noch ein Jahr zuzuwarten, dann werde sich zeigen, welches der Verfahren sich am besten zur Zuckergewinnung aus Runkelrüben eignen werde.

Jobst äußerte sich auch kritisch zu den Versuchen in der Ettlinger Zuckerfabrik, die im Februar 1837 gemacht wurden und zweifelte, ob die Ergebnisse der Zuckergewinnung nach der Schützenbach'schen Methode wirklich korrekt ermittelt worden seien ${ }^{135}$. Auf der Rückreise hatte er nämlich gehört, dass bei diesen Versuchen keine getrockneten Runkelrüben, sondern lediglich über vier Monate alte, in Gruben gelagerte Rüben verwendet worden waren, was ein eindeutiger Verstoß gegen die Regeln und Abmachungen des Probebetriebs war. Auch habe man Rüben in so großen Mengen zu einem Preis von 30 xr je Zentner eingekauft, welche aber nicht

135 Vgl. Anm. 67. 
alle getrocknet werden konnten, sondern in Gruben eingelagert wurden, wo sie beinahe verdarben, sodass sie wieder um 6 xr als Viehfutter verkauft werden mussten, ein großer Schaden, der so nicht hätte eintreten müssen, wenn die Ettlinger Direktoren sorgsamer mit dem Ankauf der Runkelrüben umgegangen wären.

Um den Bericht des Kommerzienrates Jobst abzuschließen, sei erwähnt, dass er im Innenministerium sorgfältig studiert und zur Kenntnis genommen wurde, vor allem erregte die Notiz Aufmerksamkeit, der Fabrikdirektor Bensen und der Ingenieur Brinjes seien nicht abgeneigt, nach Württemberg zu kommen. Innenminister Schlayer schrieb daher dem württembergischen Gesandten Graf von Mandelsloh in London, er möge den Hofdomänenrat August von Weckherlin, der sich gerade auf dem Weg nach England befinde, um dort die englische Landwirtschaft kennenzulernen, anweisen, dass er weitere Erkundigungen über die Londoner Runkelrüben-Zuckerfabrik einziehe, vor allem aber eine Zeichnung des Macerators von Bensen und Brinjes besorge. Zudem möge Weckherlin herausfinden, ob Bensen und Brinjes tatsächlich geneigt seien, ein Engagement bei einer württembergischen Unternebmung anzunehmen ${ }^{136}$. Nun, ob Weckherlin die geforderte Zeichnung lieferte, ist nicht bekannt, auch nicht, ob Bensen und Brinjes jemals ernsthaft erwogen hatten, nach Württemberg zu wechseln.

Dank dieser Notizen des Kommerzienrates Jobst können Verbindungen und Strukturen aufgezeigt werden, die den Schluss zulassen, dass die Regierung ein massives Interesse hatte, die in Württemberg nicht vorhandenen theoretischen und technischen Kenntnisse auf legalen und weniger legalen Wegen über Mittelsmänner zu erwerben. Auf diese Weise gelangte auch das nicht ausreichend erprobte Verfahren des Freiburger Fabrikanten Schützenbach nach Württemberg. Im Hintergrund wirkten indes noch andere Interessenten an der Verbreitung des Schützenbach'schen Verfahren mit, vor allem Finanzkreise, die Kredite zum Aufbau der neuen Industrie gewährten. Genannt wurden besonders die Bankhäuser Haber und Gontard. Über den Aktienhandel und die Kreditvergabe lassen sich Verbindungen zur Geldaristokratie und zu Bankplätzen in ganz Europa (St. Petersburg, Köln, Mannheim, Frankfurt/Main, Sachsen und München) knüpfen. Besonders das Bankhaus Haber in Karlsruhe, das von Anfang in die Verhandlungen involviert war, war seinerseits in Wechselgeschäften mit Bank- und Handelshäusern wie Rothschild, Oppenheim, Flersheim, Lindheimer und Haniel vernetzt.

Haber hatte indes nicht nur die Interessen der badischen und württembergischen Zuckergesellschaften in Auge, sondern auch jene der von ihm beherrschten badischen Unternehmen, hier insbesondere der Maschinenbauwerkstätte von Kessler und Martiensen, die in den Genuss von Aufträgen kommen sollte, obwohl sie nicht über das Knowhow für die benötigten Maschinen und Apparaturen verfügte. Dieser Mangel bedingte, dass Maschinen bei anderen Herstellern in Auftrag gegeben

136 HStAS E 70t (Gesandtschaft London) Bü 190 (Brief an Graf von Mandelsloh, datiert Stuttgart 11. Juli 1837). 
wurden. Aus Vortragsnotizen, die Louis von Haber am 7. Dezember 1847 für die Generalversammlung der württembergischen Zuckergesellschaft zu Papier brach$\mathrm{te}^{137}$, geht hervor, dass für Altshausen die Extraktionsbatterien in luftleerem Raum mit Luftpumpen (d.h. Vakuum-Extraktionswannen mit Dampf-Druckzuleitungen und Steuerungsventilen) in der Gießerei Schussenried angefertigt wurden. Diese neuartigen Vakuum-Extraktionswannen gab es nicht in Züttlingen, wo man sich noch mit Holzkonstruktionen behalf, welche aber jedes Mal ersetzt werden mussten, wenn das Hochwasser der Jagst das Siedhaus unter Wasser gesetzt hatte. Ein solch' modernes Vakuum-Extraktionssystem bestellte 1846/47 auch die Züttlinger Fabrik in Schussenried. Ferner wurde in Schussenried ein großer Dampfkessel für Altshausen gegossen. Bei der Montage all dieser Geräte waren kleine Werkstätten in Mengen, Ertingen, Weingarten, Altshausen und Waldsee beteiligt; die doppelt wirkende Luftpumpe (Guss der Zylinder in Wasseralfingen) montierte der Mechanikus Maier aus Mengen; die Dampfmaschine zum Betrieb des Trocknungshauses, die man wegen fehlender Wasserkraft aufgrund von Wassermangel installieren musste, wurde mit allen Teilen in Schussenried gegossen und von dem Mechanikus Kramer in Weingarten zusammengebaut. Lediglich die Vakuumpfannen mit ihren Luftpumpen und Rechauffoirs, aus Kupfer und Messing gefertigt, bezog man aus Berlin. Haber rechtfertigte die Anschaffung der Maschinen und Apparaturen damit, dass sie in einer Zeit (nämlich 1846/47) geschah, wo die Not am größten war und somit einige Hundert Menschen täglich beschäftigt waren. Er meinte: Bedenkt man dies alles, so wird vielleicht ein anderes Licht auf den Urbeber fallen und das Urtheil des immer so woblwollenden Monarchen, dessen Aufruf zur Beschäftigung der Notbleidenden man sebr scharf ins Auge faßte, in etwas gemildert werden. Die Verantwortlichkeit soll durch diese wenige Worte nicht im Geringsten abgewälzt werden ${ }^{138}$.

Verschwiegen kann und soll nicht werden, dass die Schützenbach'sche Extraktionsmethode keineswegs so mangelhaft war, wie man nach dem Zusammenbruch der württembergischen Zuckergesellschaft von Ende 1847 annehmen könnte. Louis von Haber erwähnt in seinen „Flüchtigen Notizen“, dass sie inzwischen die anerkannt beste sei und in Frankreich, namentlich im Département du Nord, in Zuckerfabriken eingeführt sei, wofür die badische und württembergische Gesellschaft im Verein mit ihrem Agenten in Valenciennes Lizenzgebühren von $12.000 \mathrm{fl}$ erhalten habe, und weitere Einnahmen seien durch Verträge zu erwarten. Ein unbefangener Autor beurteilte das Schützenbach'sche Verfahren 1858 mit den Worten ${ }^{139}$ :

137 Archiv des Hauses Württemberg Altshausen. Hofdomänenkammer, Zuckerfabrik Altshausen Bü 335 (Flüchtige Notizen über den Bauaufwand und die Anschaffungen von Maschinen und Apparaten für Züttlingen und Altshausen, datiert Carlsruhe, 7. December 1847, mit Unterschrift „Louis von Haber“).

138 Ebd. wie Anm. 136, S. 4 (nachträgliche Pagina).

139 Art. ,Zuckerfabrikation‘. In: Ökonomische Encyclopädie oder Allgemeines System 
Nach den bei den im Baden'schen und Würtemberg'schen nach dieser Methode von Schützenbach arbeitenden Rübenzuckerfabrikanten gemachten Erfabrungen ist sie obne Frage die vortheilhafteste unter allen, und es ist sebr wabrscheinlich, daß sie in der Folge, zumal wenn noch einige wünschenswerthe Verbesserungen an dem Trockenapparate erfunden sein werden, wobl allgemein werden wird.

Eine späte Anerkennung, für welche freilich die badischen und württembergischen Zuckerfabriken einen hohen Preis und die Fabrikdirektoren viel Lehrgeld zahlen mussten, ganz zu schweigen davon, dass sich viele der Aktionäre gewünscht hätten, sie hätten früher ordentliche Dividenden ausbezahlt bekommen und keine Verluste gemacht. Am Ende wurde aus dem Abenteuer Zuckerfabrikation aus Runkelrüben noch eine Erfolgsgeschichte. Bilden doch die badische und württembergische Zuckergesellschaft mit ihren Werken in Züttlingen, Altshausen und Waghäusl die Wurzeln der heutigen Südzucker AG, Mannheim.

der Staats-, Stadt-, Haus- und Landwirtschaft. Hg. von Johann Georg Krünitz, fortgesetzt von Friedrich Jakob Floerken. Berlin 1858. Bd. 242. S. 315. 